\title{
Experimental methods in chemical engineering: High performance liquid chromatography-HPLC
}

\author{
Dalma Schieppati*1 | Nicolas A. Patience $^{1}$ | Sebastiano Campisi ${ }^{2}$ | Gregory S. Patience ${ }^{1}$
}

${ }^{1}$ Chemical Engineering, Polytechnique Montréal, C.P. 6079, Succ. "CV", Montréal, H3C 3A7 Québec, Canada

${ }^{2}$ Dipartimento di Chimica, Università degli Studi di Milano, via Golgi 19, Milano, 20133 Milano, Italy

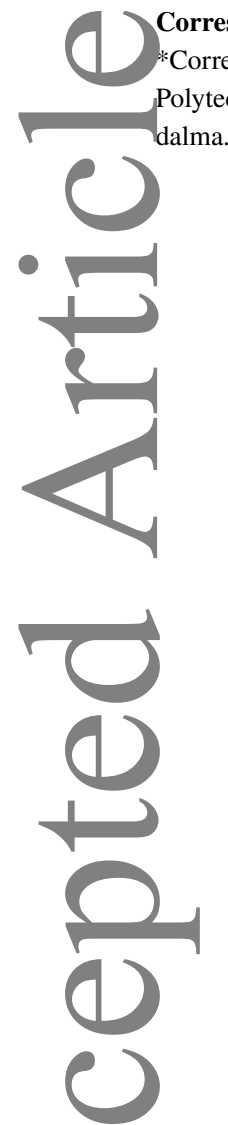

Correspondence

Corresponding author Dalma Schieppati, Polytechnique Montreal. Email: dalma.schieppati@polymtl.ca

\begin{abstract}
Summary
High performance liquid chromatography (HPLC) identifies compounds in a sample and quantifies their concentration. The instrument consists of an injector that introduces a $\mu \mathrm{L}$ sample to a mobile phase that carries the analytes across a column filled with an adsorbing substance. The analytes adsorb and desorb at different rates as they flow down the column and are thereby separated. Detectors record a signal proportional to the concentration of the analyte in the mobile phase. Laboratories apply modern HPLC systems for research and development, quality control, safety, and validation. Academia and industry resort to HPLC to purify, identify, and characterize a wide variety of molecules at all stages of a process. Developing an HPLC analytical method is a long and laborious process requiring standards, calibration curves, derivatization, and multiple tests to identify an appropriate column, stationary phase, flow rate, temperature, and mobile phase. Optimal operating conditions maintain a good resolution (high signal-to-noise ratio and low peak overlap) while minimizing analysis time. Web of Science Core Collection indexed 8900 articles in 2019, which is relatively few compared to X-ray and scanning electron microscopy. However, it is such an ubiquitous technique and we estimate that the number of articles that report it in the experimental section is an order of magnitude higher. The bibliometric analysis of the keywords identified 4 research clusters: phenolics and flavonoids, extraction and pharmacokinetics, in vitro and oxidative stress, and optimization. Here, we detail a walkthrough for the basic steps required to develop a chromatographic method.
\end{abstract}

\section{KEYWORDS:}

HPLC, method development, UV detector, sample preparation

\section{C) 1 I INTRODUCTION}

In 1903, the botanist M.S. Tswett poured plant pigment and solvent into a glass cylinder packed with fine powder (silica, chalk). ${ }^{[1-3]}$ The pigments adsorbed and desorbed at different rates so that the compounds eluted from the column separately. In 1944, Consden, Gordon, and Martin introduced paper chromatography. Their method deposits amino acids at the base of a strip of paper; capillary action migrates the solvent upwards and separates the mixture of acids. The 1970s were a turning point in liquid chromatographic technology. Various companies developed pressurized systems and columns containing small particles (from 10 microm-5 $\mu \mathrm{m}$ ) capable of rapid and accurate separations. ${ }^{[4]}$ With close to 60000 articles that mention high performance liquid chromatography (HPLC) in 2019, it is one of the most common techniques for routine product analysis. ${ }^{[5]}$

Liquid chromatography separates, identifies, and quantifies multiple components in a mixture. ${ }^{[6]}$ In modern HPLC systems, pump-pressurized solvent(s) (mobile phase) elutes a

This article has been accepted for publication and undergone full peer review but has not been through the copyediting, typesetting, pagination and proofreading process which may lead to differences between this version and the Version of Record. Please cite this article as doi: $10.1002 /$ cjce. 24050 
TABLE 1 Modes of chromatographic separation and their associated functional groups

\begin{tabular}{ll}
\hline Chromatographic mode & Functional groups \\
\hline Normal phase & Silica \\
& Amino propyl \\
& Cyano \\
Reversed phase & Butyl (C4) \\
& Octyl (C8) \\
& Octadecyl (ODS, C18) \\
Anion exchange & Diethylaminoethanol (DEAE) \\
& Polyethyleneimine (PEI) \\
Cationic exchange & Quaternaryaminoethyl (QAE) \\
& Carboxymethyl (CM) \\
Size exclusion & Sulfopropyl (SP) \\
& Glycerylpropylsilane \\
Hydrophobic interaction & Divinylbenzene (DVB) \\
& Propyl (C3) \\
& Phenyl \\
\hline
\end{tabular}

with the aid of non polar mobile phases. Reverse phase-HPLC (RP) columns, on the other hand, contain a non-polar stationary phase and a polar mobile phase. They elute non-polar or mildly polar organic analytes. Proteins require an alternative method; they denature in acetonitrile or methanol and produce factitious peaks or clog the column.

Ion-exchange columns separate anionic or cationic compounds. ${ }^{111}$ Size-exclusion chromatography (SEC) separates molecules by relative size, shape, hydrodynamic volume, and viscosity. ${ }^{12]}$ The former separates phosphorylated proteins from their non-phosphorylated forms while the latter is better suited to separate aggregates from protein monomers. 13 [14

Once the chemistry of the separation is established, we excogitate the physical properties of the filling: particles size, porosity, and pore diameter. The particle size of common HPLC columns ranges from 2 microm- $10 \mu \mathrm{m} .{ }^{[8]}$ Spherical packings are 1.5-2 times more efficient than irregular ones. 15. 16 They ensure uniform paths of flow and minimize diffusion, thus reducing band broadening. ${ }^{177}$ Particle diameters of $3 \mu \mathrm{m}$ and $5 \mu \mathrm{m}$ provide the best resolution. Ultra HPLC (UHPLC) packings feature diameters smaller than $2 \mu \mathrm{m}$ for more specialized separations. Smaller packing-particle diameters increase efficiency and resolution (narrower peak width) and withstand faster flow rates with minimal loss in resolution. ${ }^{[18]}$ However, they are more clog-prone because pressure drop $(\Delta P)$ increases with the inverse of the square of the particle diameter $\left(d_{\mathrm{p}}{ }^{2}\right)$ (Equation $(4)$ ) and the back pressures are appreciable:

$$
\Delta P=\frac{150 \mu Q L}{d_{\mathrm{p}}^{2} D_{\mathrm{c}}^{2}}
$$

where, $\mu$ is the viscosity of the mobile phase, $Q$ is the flow rate of the mobile phase, $L$ is the column length, and $D_{\mathrm{c}}{ }^{2}$ is the column diameter.

Aside from bead size, the material of the stationary phase affects selectivity, which has a greater impact on resolution than the particle diameter. Well-known materials include silica, hydroxyapatite, and polymeric resins. Ideally, the stationary phase's composition is similar to the molecule(s) in question. Common hydrophobic alkyl chains come in different lengths (e.g., C4, C8, and C18), and each has a different selectivity towards the analyte. C18 alky-based phases are the gold standard for RP-HPLC. They are popular for separating peptides or small molecules, while $\mathrm{C} 4$ is better suited for proteins. ${ }^{[19}$ Phenyl-type stationary phases promote charge transfer via $\pi-\pi$ interactions. The hydrogen bonding capacity of biphenyl phases is higher than a standard C18. ${ }^{20]} \mathrm{A}$ new silica-based material called superficially porous particles (SPPs or core-shell particles) achieves the same resolution of a normal sub $2 \mu \mathrm{m}$ material but it operates at $32 \%$ lower back pressure. 21]

Porosity and pore diameter also play a role in determining chromatographic-column efficiency. The diameter and quantity of pores affect band broadening and loading capacity. Nonporous packings prevent stagnation of the mobile phase within pores and ensure better mass transfer, thus avoiding band broadening. ${ }^{8]}$ On the other hand, pore deficiency decreases surface area and loading capacity. Pore diameter and surface area are inversely proportional (Table 2). Molecules possessing identical diameters as the pores hinder diffusion. Pores with slightly larger diameters than the solute ensure maximal column loading. The ideal pore size should be at least 4-10 times the hydrodynamic diameter of the analyte. However, the optimal analyte-radius to pore-radius $(a / r)$ ratio specifically depends on the analyte nature and analysis conditions. 22]

TABLE 2 Effect of pore diameter on surface area ${ }^{3}$

\begin{tabular}{cc}
\hline $\begin{array}{c}\text { Pore diameter } \\
(\mathrm{nm})\end{array}$ & $\begin{array}{c}\text { Surface area } \\
\left(\mathrm{m}^{2} \mathrm{~g}^{-1}\right)\end{array}$ \\
\hline 10 & 250 \\
30 & 100 \\
100 & 20 \\
400 & $5-10$ \\
\hline
\end{tabular}


Column lengths are sample and separation methodology dependent; longer ones have higher separation efficiencies but at the cost of analysis time. In addition, back pressure restricts their total practicable length. Therefore, column lengths that balance resolution and analysis time are optimal. Normal phase and reverse phase HPLCs operate best with lengths of $50 \mathrm{~mm}$ $250 \mathrm{~mm}$, whereas $300 \mathrm{~mm}$ is best for SEC.

\section{2 | Mobile phase: Retention and selectivity}

The column chosen for the separation process determines the necessary mobile phase. In RP-HPLC, the mobile phase must be polar in order to separate analytes in the nonpolar stationary phase. Polar solutes prefer polar mobile phases; the columns quickly release them (smaller $k$ ). However, non-polar solutes interact preferentially with the solid material, which readily retains them (larger $k$ ). For example, resorcinol has a dipole moment of $2.07 \mathrm{D}$ and elutes faster than vanillin, which has a dipole moment of 1.74 D (Figure 2). 23] 24]

Often, the mobile phase is a mixture of solvents. These mixtures, whether organic or inorganic, ensure efficient separation (acceptable retention and selectivity). Initially, an HPLC method for an unknown sample may yield useless chromatograms despite a suitable stationary phase. In this case, modify the composition of the mobile phase to modulate its polarity and adjust $k$. Generally, a polar mobile phase contains an organic (e.g., acetonitrile, methanol) and inorganic solvent (e.g., water). The percentage of organic solvent influences $k$; a low percentage yields successful separations. The nature of the organic solvent, on the other hand, affects the selectivity for the analytes.

Solute retention varies with $\mathrm{pH}$ when its value is \pm 1.5 units from the solute's $\mathrm{p} K_{\mathrm{a}} \cdot{ }^{[2]}$ Otherwise, $\mathrm{pH}$ 's effect on separation selectivity is null. $\mathrm{pH}$ change in the mobile phase increases solute ionization and elution rate. Fine tuning the $\mathrm{pH}$ is essential when it comes to developing a method for ionic compounds, particularly in RP-HPLC where ionized species elute before neutral species. If the $\mathrm{pH}$ of the mobile phase changes with time, the results will be inconsistent. We recommend adding a buffer to the mobile phase to maintain a constant $\mathrm{pH}$. Buffers are composed of a weak acid (or weak base) and its conjugate base (or acid) in at least $50 \%$ aqueous solution. This pair exists in equilibrium and shifts accordingly to preserve the same $\mathrm{pH}$ when an acid or base is added. The selected buffer should have a $\mathrm{pH}$ with at least 2 units difference from the $\mathrm{p} K_{\mathrm{a}}$ of the analyte. Otherwise, peaks might split or present shoulders. If the analyte is acidic, it will elute in the ionic form only if the $\mathrm{pH}$ of the mobile phase is above its $\mathrm{p} K_{\mathrm{a}}$. In contrast, if the analyte is basic, it will elute in the ionic form if the mobile phase's $\mathrm{pH}$ is lower than its $\mathrm{p} K_{\mathrm{a}}$. When working with mixtures of analytes, it is desirable to work at a $\mathrm{pH}$ at which all the compounds exist in the same form, either ionic or not. In RPHPLC, acids separate better in the neutral form and bases in the charged form. Popular buffers for UV detectors are acetate and phosphate because of their low cut-off wavelengths (below $220 \mathrm{~nm})$.

In addition to $\mathrm{pH}$, additives and salts in the mobile phase alter the cut off wavelength (see Section 3.1. Ultravioletvisible). Impure HPLC solvents produce background absorbance and baseline drift. ${ }^{[25}[26]$ Furthermore, we do not advise introducing minerals into MS (mass spectrometry) detectors because they present volatility issues. Acceptable volatile buffers are ammonium salts (e.g., ammonium acetate, ammonium citrate, ammonium formate). Acetic acid and formic acid act as modifiers rather than buffers, but they often control the $\mathrm{pH}$ as well as ionization in MS systems (Table 3).

TABLE 3 Common buffers for high performance liquid chromatography (HPLC)

\begin{tabular}{lcc}
\hline Buffer & $\mathrm{pH}$ range & MS compatible \\
\hline Acetate & $3.8-5.8$ & as ammonium salt \\
Ammonium formate & $2.7-4.7$ & YES \\
Ammonium bicarbonate & $6.6-8.6$ & YES \\
Borate & $8.3-10.3$ & YES \\
Citrate $\left(\mathrm{p} K_{1}\right)$ & $2.1-4.1$ & NO \\
Citrate $\left(\mathrm{p} K_{2}\right)$ & $3.7-5.7$ & NO \\
Citrate $\left(\mathrm{p} K_{3}\right)$ & $4.4-6.4$ & NO \\
Formic acid $(0.1 \%)$ & 2.7 & YES \\
Phosphate $\left(\mathrm{p} K_{1}\right)$ & $1.1-3.1$ & NO \\
Phosphate $\left(\mathrm{p} K_{2}\right)$ & $6.2-8.2$ & NO \\
Phosphate $\left(\mathrm{p} K_{3}\right)$ & $11.3-13.3$ & NO \\
Phosphoric acid $(0.1 \%)$ & 2.0 & NO \\
TFA $(0.1 \%)$ & 2.0 & YES \\
\hline
\end{tabular}

Low mobile phase flow rates maximize resolution. ${ }^{[28}$ However, when the flow rate is too low, peaks broaden. ${ }^{29}$ A balance between column type (length and particle size) and peak capacity ensures an ideal flow rate; column product data sheets indicate this flow rate. For example, a $250 \mathrm{~mm}$ long, $4.6 \mathrm{~mm}$ diameter RP-HPLC column's optimal mobile phase velocity is $1 \mathrm{~mL} \mathrm{~min}^{-1}$. In addition, an ultrasonic bath removes air bubbles from the mobile phase and prevents baseline drift, disturbance at void time, and signal noise; a back-pressure regulator, installed on the detector, has a similar function.

\section{3 | Temperature}

Increasing the temperature in HPLC has a similar effect as small particle packings. At ambient temperature, columns 
reach the upper pressure limit of the chromatographic system because of high backpressure and mobile phase flow rates. Increasing temperature reduces analysis time and enhances resolution, efficiency, and selectivity. The viscosity of the mobile phase decreases with increasing temperature reducing flow resistance and thus backpressure. Viscosities lower than $0.001 \mathrm{~Pa}$ s and temperatures higher than $40^{\circ} \mathrm{C}$ promote diffusion, creating tall and narrow peaks. A temperature increase from $25{ }^{\circ} \mathrm{C}-50{ }^{\circ} \mathrm{C}$ narrowed the peak of vanillin by $19 \%$ and the peak of resorcinol by $17 \%$. The peak heights increased by $22.5 \%$ and $20.5 \%$, respectively (Figure 2). Moreover, RPHPLC operation at $\geq 40^{\circ} \mathrm{C}$ reduces the amount of organic solvent. For example, a $5{ }^{\circ} \mathrm{C}$ increase corresponds to a $1 \%$ change in acetonitrile in RP-HPLC with C18-silica packings. ${ }^{30]}$

However, high temperature adversely affects analyte stability. Biological samples are sensitive to heat. Hormones, such as cortisol and testosterone, degrade above $37^{\circ} \mathrm{C}$. 31$]$ Above $45^{\circ} \mathrm{C}$, proteins undergo conformational changes; on the plus side it could cause a narrowing of the peaks and increased symmetry, or, on the negative side, loss of solubility and subsequent aggregation of the macromolecules, which clogs columns. ${ }^{[2]}$ Moreover, most LC columns should not operate above $60^{\circ} \mathrm{C}-70^{\circ} \mathrm{C}$ for long periods of time. At temperatures above $80^{\circ} \mathrm{C}$, the backbone of silica-based stationary phases decomposes, that is, the column bleeds. 32$]$ Nevertheless, Macko et al separated atactic and syndiotactic polypropylene at $160^{\circ} \mathrm{C}$ with a porous graphitic carbon stationary phase. 33
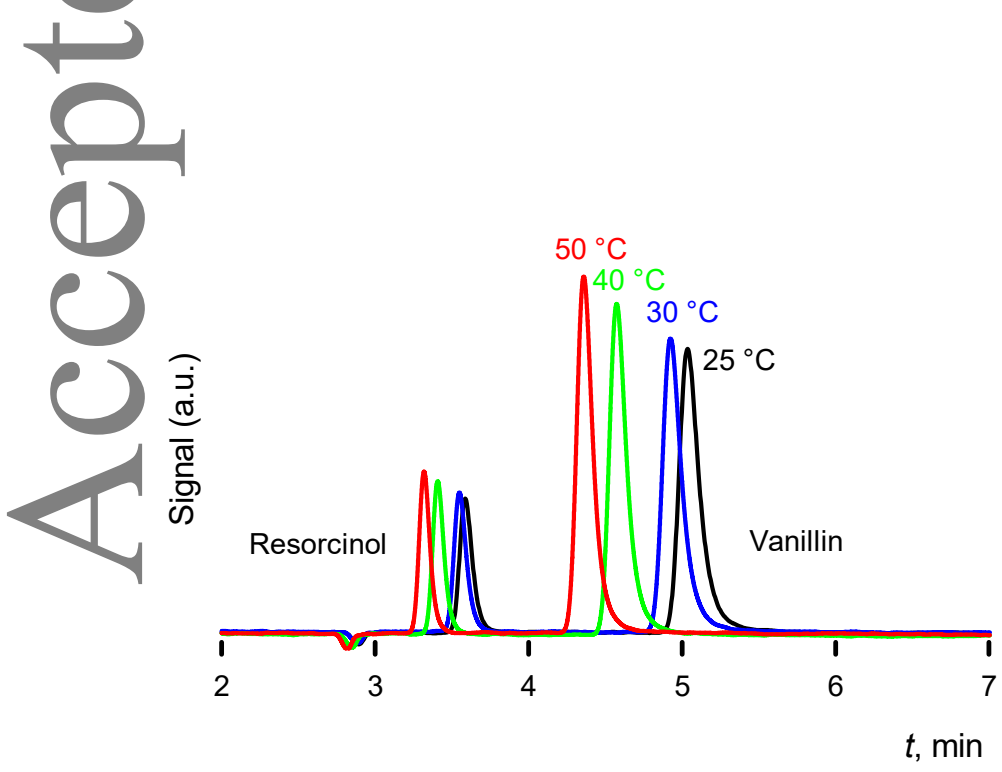

FIGURE 2 Chromatogram of a $10 \mu \mathrm{L}$ aqueous solution of vanillin $\left(12 \mu \mathrm{g} \mathrm{g}^{-1}\right)$ and resorcinol $\left(12 \mu \mathrm{g} \mathrm{g}^{-1}\right)$ with a Microsorb MV 100-5 C18 $(250 \mathrm{~mm} \times 4.6 \mathrm{~mm})$ column and water/methanol $(60: 40)$ at $1 \mathrm{~mL} \mathrm{~min}{ }^{-1}$. Photo-diode array detectors (DAD) detection at $230 \mathrm{~nm}$

\section{3 | DETECTORS}

Detectors generate an electrical signal proportional to the concentration of the molecule; they are responsible for the qualification and quantification of the analytes after separation. An ideal detector generates a linear response with concentration without contributing to band spreading, is non-destructive, is responsive to analytes across the entire concentration gradient of the samples, and maintains a zero baseline. Current detectors achieve most of these criteria. Detection modes have specific selectivity and sensitivity and we choose detectors based on the nature of the analyte and chromatographic method (Table 4). For example, some analytes are detectable only after derivatization. [34]37]

TABLE 4 Modes of detection for HPLC

\begin{tabular}{|c|c|c|}
\hline Detector & Response & Application \\
\hline UV-Vis & Selective & Pharmaceuticals \\
\hline RI & Universal & $\begin{array}{l}\text { Carbohydrates, alcohols, } \\
\text { fatty acids, hydrocarbons }\end{array}$ \\
\hline MS & Universal & $\begin{array}{l}\text { Biomolecules } \\
\text { MW determination } \\
\text { Structure determination } \\
\text { Pharmacokinetic studies }\end{array}$ \\
\hline Light scattering & Universal & $\begin{array}{l}\text { Polymers } \\
\text { MW determination }\end{array}$ \\
\hline Fluorescence & Selective & Aromatics \\
\hline Radioactivity & Selective & Pharmacokinetic studies \\
\hline Electrochemical & Selective & Biological metabolites \\
\hline
\end{tabular}

\section{1 | Ultraviolet-visible}

UV-Vis irradiates UV light at selected wavelengths in a glass flow cell where the eluted sample enters. If the analyte contains chromophore(s), it absorbs part of the irradiated UV light ${ }^{[26]}$; the detector registers a lower radiation intensity in the presence of the analyte as opposed to the pure mobile phase. The BeerLambert law states that the absorbance of a molecule is directly proportional to its concentration and molar absorptivity $(\epsilon)$. $\epsilon$ is molecule-specific and depends on structure and detection wavelength.

Photo-diode array detectors (DAD) simultaneously record a large interval of wavelengths (entire spectrum) and generate a three-dimensional graph (absorbance vs. time vs. wavelength). DAD is more informative and less time consuming than monochromatic (single wavelength) detection. 38 
UV-Vis is sensitive $\left(10^{-11} \mathrm{~g}-10^{-12} \mathrm{~g}\right)$ and selective for molecules that absorb between $190 \mathrm{~nm}-750 \mathrm{~nm}$. Despite the low background noise for common HPLC solvents, there is a minimum working wavelength for mobile-phase absorption dubbed the cut off $\lambda_{\text {co }}$. This detection mode best suits molecules with aromatic rings as they absorb well in the UV-Vis range. ${ }^{39} 40$ The industry of fine chemicals (i.e., pharmaceuticals, proteins, peptides, and plant extracts) relies on it. $41[42]$

\section{2 | Refractive index}

Refractive index (RI) detectors compare the refractive index $(n)$ of the mobile-phase containing analyte (flowing in the sample cell) to the pure mobile phase (flowing in the reference cell). The greater the $\Delta n$ between the sample and mobile phase, the larger the imbalance between them and the higher the sensitivity of the detector. The sensitivity of RI detectors is in the range of $\mathrm{m} \mathrm{L}^{-1}$. [2] $\mathrm{RI}$ is meant for isocratic separations; it does not compensate for baseline changes caused by variations in the composition of the mobile-phase. RI detectors identify all analytes except those with a similar RI as the solvent. In complex mixtures, analytes may cover a wide range of $n$ values, some close to the mobile phase rendering them invisible to the detector. This technique is for molecules that are transparent to UV-Vis, that is, carbohydrates (fructose and glucose) and hydrocarbons. The RI detector should be continuously active to minimize temperature and pressure variations, which decrease sensitivity and prompt baseline noise or ripples. Hand-mixed mobile phases yield flatter baselines than instrument-mixed solvents.

\section{3 | Mass spectrometry}

Mass spectrometry (MS) is highly selective and suitable for ionizable compounds. ${ }^{[43]}$ Molecules gain or lose a proton in its ionization interface. The mass analyzer captures ions and then generates, sorts, and resolves signals that are proportional to their mass-to-charge ratios $(\mathrm{m} / \mathrm{z})$. The limit of detection (LOD) is in the order of pico-moles and supports molar masses even above $100000 \mathrm{Da}$. MS is often coupled with RP-HPLC because the mobile phase must be volatile. Ideal flow rates range from $1 \mu \mathrm{L} \mathrm{min}^{-1}-20 \mu \mathrm{L} \mathrm{min}^{-1}$ to allow the effluent time to vaporize. As a result, HPLC-MS systems implement microbore or capillary columns to split the output stream. 444]45] They identify degradation products in wastewater treatment and screen biomacromolecules. ${ }^{46}$ 49] A variety of ion sources and mass analyzers are available depending on the budget and application. 50

\section{4 | Light scattering}

Light scattering devices detect the light deflected by matter. The electromagnetic radiation travels through a non-uniform medium, which changes its straight trajectory. Light excites molecules and generates a temporary dipole that oscillates the atoms. Molecules emit light in all directions as they return to their ground state. The relative light intensity relates to the Rayleigh factor $\left(R_{\theta}\right)$, which is a measure of scattered radiation. 51$]$ Concerning the mobile phase, the excess $R_{\theta}$ relates to the molecular weight, solute concentration, RI, and incident light wavelength. This technique works for isocratic (constant mobile phase composition) and gradient (varying mobile phase composition) elutions.

Multi-angle laser light scattering (MALLS) measures scattering at multiple angles; the total scattered light is directly proportional to the sample's concentration and molar mass. MALLS coupled with UV and RI identifies the aggregation status of samples, especially with proteins.

Evaporative light scattering detectors (ELSD) detect all compounds that are less volatile than the eluent. The ELSD sprays the effluent and heats the nebulized mist to evaporate the mobile phase. The less volatile analytes flow through a cell exposed to light. Droplet size is important. A larger droplet requires a higher evaporation temperature but scatters more radiation. ${ }^{[53}$ In contrast, a smaller droplet and thus a lower evaporation temperature promotes crystallization of the sample that increases sensitivity. The correlation between signal and sample concentration is logarithmic with ELSD; the peak area depends on droplet size, solute properties, liquidand gas-phase flow rate, and temperature more so than solute concentration.

Light scattering techniques are particularly handy when analyzing polymers with size exclusion chromatography (SEC). Accuracy is high for molecular weights above $10000 \mathrm{Da}$ but this detection mode is not suited for values below $5000 \mathrm{Da}$. The higher the molecular weight of the analyte, the more sensitive the detector. At high molecular weight the LOD ranges from $10^{-4} \mathrm{~g}-10^{-6} \mathrm{~g}$.

\section{5 | Fluorescence}

Fluorescence detectors energize molecules to their excitation wavelength $\left(\lambda_{\mathrm{ex}}\right)$ in the UV region and subsequently detect the emitted radiation $\left(\lambda_{\mathrm{em}}\right)$ in the visible spectrum. Fluorescence works best with benzene and its derivatives, and varies with ring substitution. Common naturally fluorescent compounds are hormones (e.g., estrogens), vitamins (e.g., vitamin A), phenols, aromatic amino acids (tryptophan and tyrosine), flavins, and toxins (e.g., aflatoxin).

Despite its sensitivity to mobile phase composition and $\mathrm{pH}$, fluorescence is 100-1000 times more sensitive than UV-Vis ${ }^{54}$ 
and offers excellent selectivity and detection limits below $1 \mathrm{pg}$; it is the ideal technique to determine contaminants in environmental and food samples. $55,[58]$

\section{6 | Radioactivity}

These detectors count the radioactivity of the solution containing the analyte as it flows through the cell of the device. Unlike $\mathrm{RI}$, radiochemical detectors are insensitive to variations in solvent composition, which make them useful in gradient elution analyses. Although this detection method is highly selective because it only traces appropriately labelled molecules, it is unpopular because of the contamination risk of the effluent. However, pharmacology adopts it to study the pharmacokinetics of tagged metabolites, such as hormone receptors in cancer tissues or steroids. Radiochemical detection depends on the counting time, efficiency of the isotope label, and background radiation. The LOD is expressed as disintegrations per minute (dpm) and varies with the counting mode. Homogeneous counting (i.e., liquid scintillation counting) is 10 times more sensitive than heterogeneous counting (i.e., solid scintillation counting) (600 dpm versus $60 \mathrm{dpm}$ ). Kiffe et al provide a detailed study on radioactivity detectors for pharmacokinetic studies via HPLC. 59]

\subsection{Electrochemical}

Electrochemical detectors apply a constant potential to electroactive solutes and measure the current generated between two electrodes. The amperometric detector is the most common type; the signal varies proportionally to the concentration of analytes that oxidize or reduce. This technique is sensitive $\left(10^{-11} \mathrm{~g}\right)$, selective, and only detects molecules that react within the electrode working potential. It applies solely to isocratic elutions because a variation of the ionic concentration causes the baseline to drift. RP-HPLCs often adopt amperometric detectors because they require electrically conductive polar mobile phases that are inert and able to support electrolyte dissociation.

The detector (coulometric detector) converts and detects all molecules that can undergo reaction when it is equipped with a porous graphite electrode or at low flow rates. Electrochemical detectors also identify ions (conductivity detectors) in the analysis of organic and inorganic ions eluting from ion-exchange columns. These detectors apply a constant potential at the flow cell and measure the current over time. Their sensitivity rating is $10^{-12} \mathrm{~g}$, but they are non-selective. Electrochemical methods effectively analyze complex biological molecules like catecholamines (e.g., dopamine).

\section{4 | SAMPLE PREPARATION}

A coherent sample preparation strategy ensures consistent, reproducible, and reliable results, while maintaining the integrity of the instrument. Samples must be compatible with the HPLC unit and soluble in the mobile phase. The preparation of samples begins with collection, followed by storage and work up. Complex samples require further derivatization and/or dilution to improve the separation and resolution. Sample work-up procedures should be refined to reduce the number of steps to ensure reproducibility and minimize errors.

We classify organic and inorganic samples as solids, semisolids (e.g., gels and suspensions), liquids, and gases. HPLC requires liquid samples and therefore solid and semi-solid compounds must be solubilized, possibly in the mobile phase. Gas chromatography (GC) processes gaseous samples; however, when these samples are thermally unstable and condensible, HPLC is more reliable. Sample work-up varies with their nature and characteristics. A general procedure is:

1. Fractionation (solid or liquid extraction, precipitation)

2. Solubilization

3. Concentration and desalting

\section{Dilution}

\section{Particulate removal}

Fractionation liquefies the sample, simplifies the mixture so that the column separates within its capacity, and eliminates contaminants that would influence the chromatographic analysis(e.g., by binding to the stationary phase and altering column selectivity $\left.{ }^{600}\right)$. Size reduction of solids (e.g., grinding, milling) eases their dissolution in an appropriate solvent. Ideally, the mobile phase dissolves the solid or semi-solid material.

Solubilization often relates to stabilization. Integral membrane proteins (IMPs) are hydrophobic species embedded in the phospholipid bilayer of cell membranes. These ordered structures contain hydrophobic and hydrophilic portions. They agglomerate and precipitate, which disrupts the purification process. Surfactants stabilize these structures by binding to the hydrophobic domains of the IMPs and forming proteindetergent micelles that are stable in aqueous environments. 61 If the sample needs further purification, dialysis, solvent extraction, adsorption on resins, or affinity binding, remove the surfactant to avoid detection interference (UV especially) and to not damage the stationary phase.

Lyophilization, vacuum evaporation, or precipitation by $\mathrm{pH}$ variation concentrates the samples that were diluted in the range of the LOD of the detector. 
Centrifugation and sedimentation remove solids and semisolids from samples. However, the most common technique is filtration. A lower porosity filter produces a cleaner filtrate but increases processing time; in this case, vacuum filtration is practical. Inadequate particulate removal reduces column sensitivity and lifetime, damages injection valves and tubing, and lowers accuracy. Particulate in the liquid sample increases the background noise and induces peak tailing, which reduces resolution. Moreover, false-positive peaks may occur. Turbidimetry evaluates the effectiveness of the particulate removal technique, particularly for aqueous samples. ${ }^{[62]}$ Ultrafiltration, dialysis, reverse osmosis, and classical column chromatography are other techniques that cater to samples, depending on their characteristics. These also remove salt from proteic samples as they hinder the elution in ion exchange columns.

Snyder et al and Cunico et al provide a comprehensive set

- $\quad$ of sample preparation techniques. ${ }^{8[50]}$

\section{1 | Dilution}

Concentrated samples oversaturate the detector and generate meaningless chromatograms. Moreover, concentration change between samples overloads the column from which peak broadening arises, and thus, results in poor resolution. Dilution is the solution. Ideally, the mobile phase or a mobile-phase compatible solvent dilutes the sample. It can be by weight or volume so long as the execution is constant across dilutions. $2[8] 50$

Micropipettes or graduated pipettes and volumetric flasks are the simplest tools to dilute samples volumetrically. For weight dilutions, a variety of analytical scales are available ( $\mathrm{mg}$ to $\mathrm{kg}$ ). Dilution by parts is the standard. For example, in a 1-50 dilution, the analyte represents one part and the solvent the remaining 49 parts. In other words, $49 \mathrm{~mL}$ of the mobile phase dilutes $1 \mathrm{~mL}$ of analyte.

Diluted samples have higher resolutions (no peak broadening) because the column separates less. ${ }^{[63]}$ However, the analyte concentration must be higher than the LOD of the detector. Samples with visible colouration (e.g., dyes with a high molar extinction coefficient such as metanil yellow) require at minimum a dilution of 1-100 before injection in HPLC-UV systems. Otherwise, a $10 \times$ or $15 \times$ dilution is sufficient for clean separation and resolution (Figure 3). Oftentimes, experience guides dilution factors. We generally test various compositions to get a sense of what dilutions are appropriate because each chromatographic and detection mode require different levels.

\section{2 | Pre-injection filtration}

It is good practice to filter the processed samples before injection, regardless of the particulate removal step during the

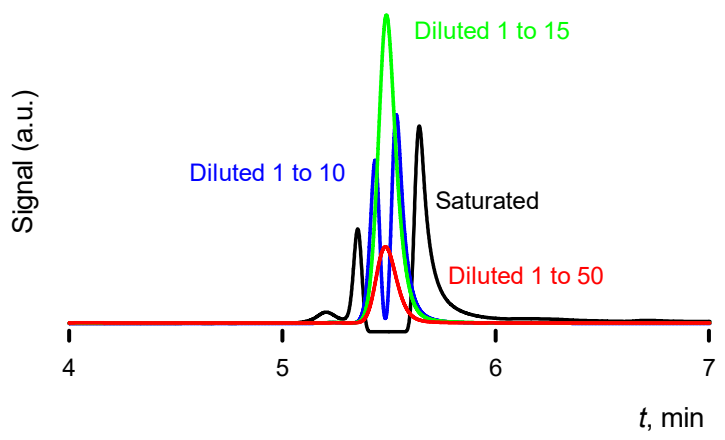

FIGURE 3 Analysis of $20 \mu \mathrm{L}$ pectin sample extracted from orange peel. Separation by Microsorb MV 100-5 C18 (250 mm $\times 4.6 \mathrm{~mm}$ ) column and water acidified with $\mathrm{H}_{2} \mathrm{SO}_{4}$ to $\mathrm{pH} 2$ at $28{ }^{\circ} \mathrm{C}$ with a flow rate of $0.5 \mathrm{~mL} \mathrm{~min}^{-1}$. Photo-diode array detectors (DAD) detection at $210 \mathrm{~nm}$

sample work-up. Otherwise, adsorbed species can block the column so that even reverse-flushing with strong solvents cannot unclog it. The selection of an appropriate filter is frequently underestimated and creates impractical results. Companies offer a copious amount of syringe filters. The nature of the sample determines the syringe membrane material (Table 5) whereas the volume determines the dimension of the filter (Table 6).

Polytetrafluoroethylene (PTFE) membranes are hydrophobic and resist aggressive solvents (e.g., THF and DMSO); they are universally applicable barring samples that contain water. Polypropylene (PP) is a suitable option for routine analysis of water-based samples; it is hydrophilic and resists acids and bases. Biological samples, like proteins, prefer polyvinyldene difluoride (PVDF), regenerated cellulose (RC), and cellulose acetate membranes for lack of binding issues. Glass microfibers are effective to pre-treat heavily contaminated samples such as DNA from biological specimens. Many companies provide online filter-solvent compatibility charts. 64.65]

Common membrane pore sizes are $0.1 \mu \mathrm{m}, 0.22 \mu \mathrm{m}$, $0.45 \mu \mathrm{m}, 0.8 \mu \mathrm{m}$, and $5 \mu \mathrm{m}$. 66

\section{5 | APPLICATIONS}

HPLC is a workhorse of chemical engineering laboratories that quantifies species' concentration in the liquid phase (e.g., catalysis, water treatment, environmental, biomedical, biotechnology, and polymers); it is so common that rarely do we mention it as part of keywords. ${ }^{67]}$ In 2019 Web of Science 
TABLE 5 Syringe filter membranes and recommended applications

\begin{tabular}{lll}
\hline Material & Recommended & Not recommended \\
\hline \multirow{4}{*}{ PTFE } & Strong acids, & Aqueous samples, \\
& alcohols, bases & benzyl alcohol, \\
& aromatics, & fluorine, \\
& DMSO, THF & diethylamine
\end{tabular}

\begin{tabular}{|c|c|c|}
\hline PES & $\begin{array}{l}\text { alcohols, } \\
\text { proteins, peptides }\end{array}$ & $\begin{array}{l}\text { esters, } \\
\text { halogenated HC } \\
\text { aromatic HC }\end{array}$ \\
\hline Nylon & $\begin{array}{l}\text { Bases, THF, } \\
\text { alcohols, DMSO, } \\
\text { aromatic HC, } \\
\text { common LC solvents }\end{array}$ & $\begin{array}{l}\text { Acids, } \\
\text { halogenated } \mathrm{HC}, \\
\text { proteins }\end{array}$ \\
\hline PVDF & $\begin{array}{l}\text { Alcohols, } \\
\text { weak acids, } \\
\text { proteins, peptides }\end{array}$ & $\begin{array}{l}\text { Strong acids, } \\
\text { bases, esters, } \\
\text { ketons, ethers }\end{array}$ \\
\hline PP & $\begin{array}{l}\text { Acids, bases, } \\
\text { organics, } \\
\text { aqueous samples }\end{array}$ & $\begin{array}{l}\text { Chloroform, } \\
\text { chloromethane }\end{array}$ \\
\hline $\mathrm{RC}$ & $\begin{array}{l}\text { Biomolecules, } \\
\text { proteins, peptides }\end{array}$ & $\begin{array}{l}\text { Strong acids, } \\
\text { chloroform, THF }\end{array}$ \\
\hline $\begin{array}{l}\text { Cellulose } \\
\text { acetate }\end{array}$ & $\begin{array}{l}\text { Aqueous solution, } \\
\text { biological samples, } \\
\text { proteins }\end{array}$ & $\begin{array}{l}\text { Organic solvents, } \\
\text { strong acids, } \\
\text { halogenated HC }\end{array}$ \\
\hline $\begin{array}{l}\text { Glass } \\
\text { microfiber }\end{array}$ & $\begin{array}{l}\text { High particulate } \\
\text { content }\end{array}$ & Benzyl alcohol \\
\hline
\end{tabular}

Core Collection (WoS), of indexed 8850 documents that mentioned HPLC in the Topic search query, only two were in the Can. J. Chem. Eng.: "Adsorption for perfluorooctanoic acid with graphitic-phase carbon nitride and its HPLC fluorescence determination", and "Photocatalytic degradation of dimethyl sulphoxide by $\mathrm{CdS} / \mathrm{TiO} 2$ core/shell catalyst: A novel measurement method". $[55] 68]$ There are the references to HPLC in 2016 and 2017 in the WoS in the field Topic, but 23 articles mention it in the methods section of the Can. J. Chem. Eng. papers; we apply HPLC an order of magnitude more than it is mentioned as a keyword. HPLC is. ${ }^{[5]}$ Perhaps as many as 100000 studies employ the technique, but researchers in the analytical chemistry, food science \& technology, pharmacology \&
TABLE 6 Syringe filter dimensions, pore size, and filterable volume

\begin{tabular}{cc}
\hline $\begin{array}{c}\text { Membrane diameter } \\
(\mathrm{mm})\end{array}$ & $\begin{array}{c}\text { Filterable volume } \\
(\mathrm{mL})\end{array}$ \\
\hline 4 & $0.5-1$ \\
10 or 13 & $\leq 10$ \\
25 or 28 & $\leq 25$ \\
30 or 33 & $\leq 100$ \\
\hline
\end{tabular}

pharmacy, biochemistry \& molecular biology industries, publish work with it most, as they mention it in $1789,1493,1389$, and 1152 articles, respectively. The top five journals in 2019 were Molecules, Food Chemistry, Journal Of Pharmaceutical and Biomedical Analysis, Journal Of Chromatography A, and Microchemical Journal, with 320, 184, 146, 134, and 130 articles, respectively.

VOSViewer software generated a bibliometric map based on the co-citations of keywords (Figure 4). 69 The software identified four research clusters: the red cluster, centered around in-vitro, oxidative stress, and purification has 36 keywords (occuring in 5385 articles); the green cluster relates most to extraction, pharmacokinetics, and human plasma and also has 36 keywords (occuring in 5888 articles); phenolics, flavonoids, and acid dominate the blue cluster with 24 keywords that appear in 4565 articles; and finally, the yellow cluster has two keywords: optimization and RSM (response surface methodology), and appears in 341 articles. The most popular techniques were found based on this word map classification and on how frequently they are mentioned in our sample: RP HPLC was mentioned most (195 articles), followed by HPLC-MS (152), HPLC-MS-MS (110), LC-MS-MS (102), LC-MS (97), and HPLC-DAD (151).

The three most cited articles in 2019 deal with extraction of acrylamide in food (green cluster, polymers and green synthesis), ${ }^{[70}$ tert-butylhydroquinone and folic acid sensor (as this is a type of phenol it belongs to the blue cluster and it mentions graphene oxide and nanocomposites), 71 and organic pollutants degradation (green cluster, and it mentions nanoparticles and photocatalysis).

In chemical engineering, the hottest topics are similar: nanocomposites, photocatalysis, and degradation. "Construction of heterostructured $\mathrm{CuFe}_{2} \mathrm{O}_{4} / g-\mathrm{C}_{3} \mathrm{~N}_{4}$ nanocomposite as an efficient visible light photocatalyst with peroxydisulfate for the organic oxidation", [73] "Fabrication of $\mathrm{Ag}_{3} \mathrm{VO}_{4}$ decorated phosphorus and sulphur co-doped graphitic carbon nitride as a high-dispersed photocatalyst for phenol mineralization and E-coli disinfection", ${ }^{74}$ and "Rational design and synthesis of hollow $\mathrm{Co}_{3} \mathrm{O}_{4} @ \mathrm{Fe}_{2} \mathrm{O}_{3}$ core-shell nanostructure for the 


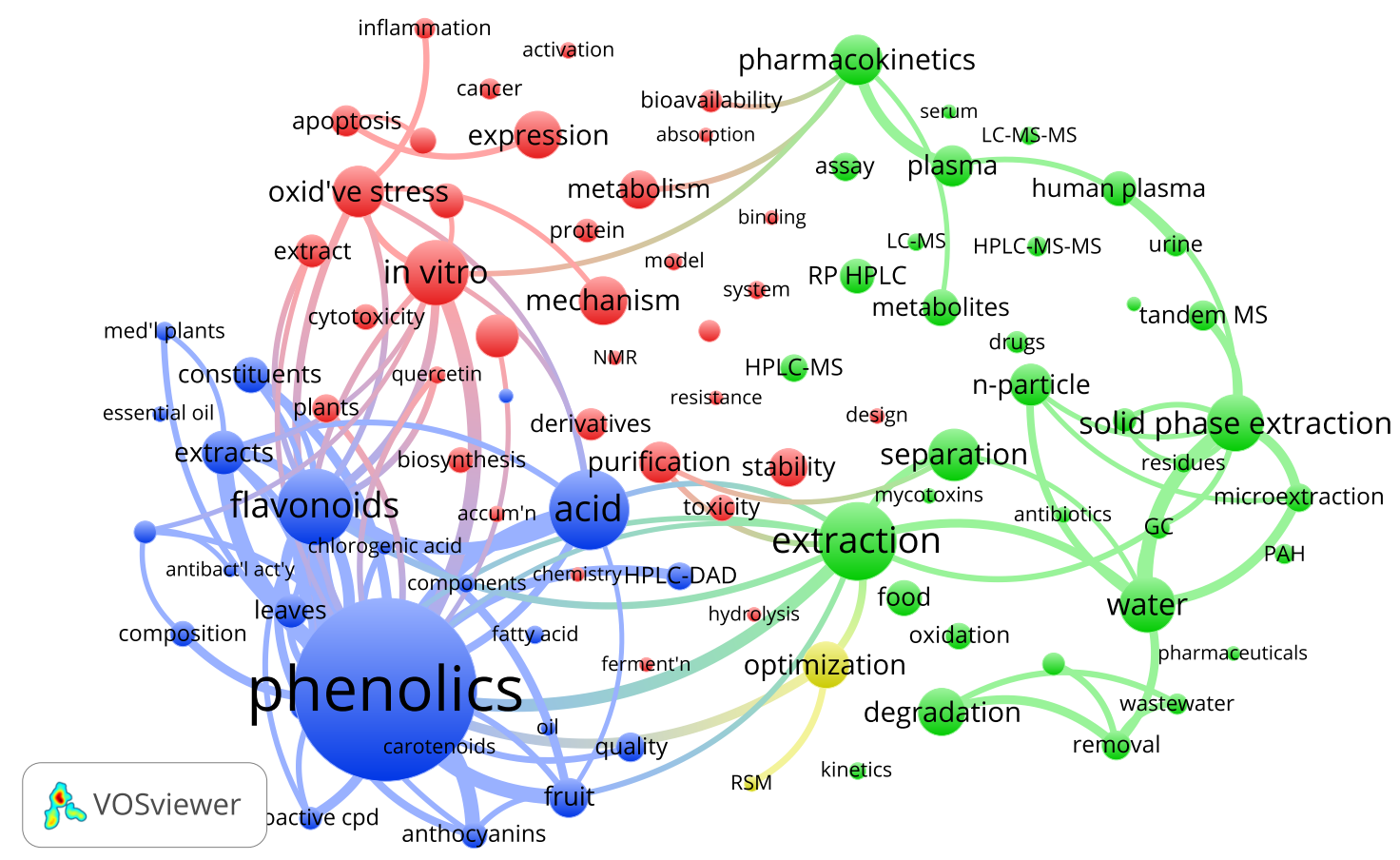

FIGURE 4 HPLC VOSviewer bibliometric co-citation map of keywords. The data base comprises the top 100 keywords of 8850 articles that mention HPLC in 2019. $67 \mid 69]$ The largest circles, which represent the number of articles that mention HPLC, include phenolics (1017 including polyphenols) in the blue cluster, extraction (437 articles) in the green cluster, in vitro (366 articles) in the red cluster, and optimization (258 articles) in the yellow cluster, which only has two keywords. We excluded HPLC with 2206 articles as its size overwhelms the map and is redundant as all articles relate to HPLC. We also excluded antioxidant (1196 articles) as it also takes up too much space, ID (564), LC (444), and performance (187). The smallest circles represent 79 articles (meaning that in 8850 articles these keywords appear in 79 independent articles) and include adsorption and NMR in the red cluster and serum, pharmaceuticals, and capillary electrophoresis in the green cluster. The software assigns colours to keywords that are related and positions them in close proximity

.

catalytic degradation of norfloxacin by coupling with peroxymonosulfate" 75 , are the most cited articles, per respective keyword. Multidisciplinary chemistry and applied chemistry are the only two WoS categories that HPLC has in common with the top categories that publish work in chemical engineering. ${ }^{76]}$ Of the 8850 HPLC articles, 263 articles are in journals assigned to chemical engineering and another 2000 are in journals that relate to chemical engineering, such as multidisciplinary and applied chemistry. Although the HPLC connection to the field is rather weak, the main keywords are similar (Figure 5).

\section{6 | UNCERTAINTY}

The IUPAC defines uncertainty as "parameter, associated with the result of a measurement, that characterizes the dispersion of the values that could reasonably be attributed to the measurand". ${ }^{77]}$ It is the estimation of the degree of confidence in the results and represents the accuracy of an analysis. ${ }^{[7}$ Uncertainty plays a crucial role in the validation of chromatographic methods and its assessment is necessary to provide accurate results. Sources of error in an HPLC analysis include sample handling, incompatibility of injection solvent and mobile phase, as well as the impurity and instability of analytes ${ }^{178}$. Flow rate fluctuations induce detector noise and create error in peak height and area.

\section{1 | Detection and quantification limits}

Detectors can limit the response, where the response is the rate of signal generated versus the concentration of the sample in the detector (sensitivity). Each detector has a threshold of detectable quantity of analyte, which is expressed as LOD and limit of quantification (LOQ). They relate to the signalto-noise ratio $(\mathrm{S} / \mathrm{N})$, where $\mathrm{N}$ is the variation of the output signal (e.g., electronics, air bubbles, temperature, pumping). The LOD is the smallest quantity of analyte discerned from the 


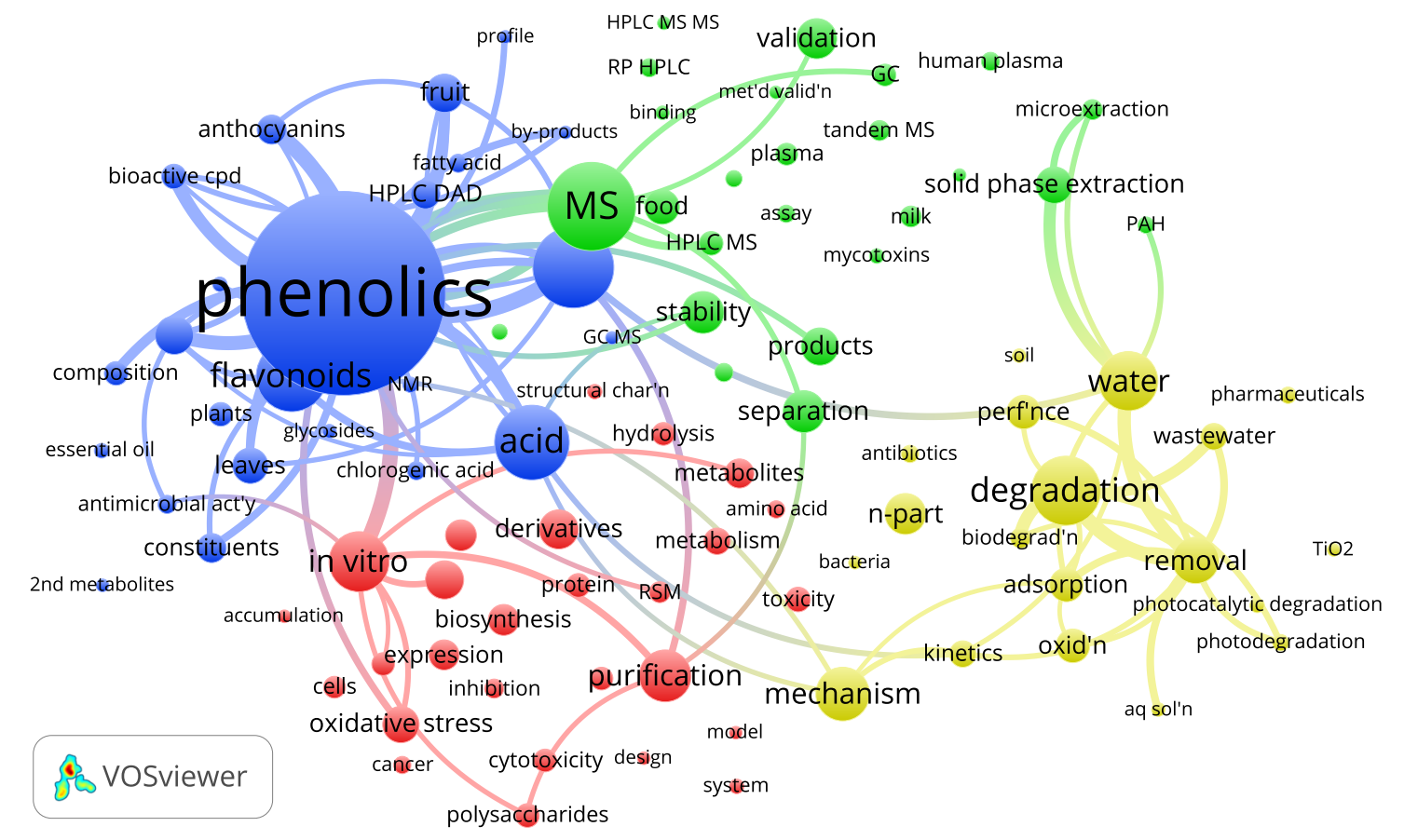

FIGURE 5 HPLC VOSviewer bibliometric co-citation map of keywords for WoS categories that have the most synergy with chemical engineering. The data base comprises the top 100 keywords of 8850 articles that mention HPLC in 2019. 67 69 The largest circles, which represent the number of articles that mention HPLC, include phenolics ( 245 including polyphenols) in the blue cluster, extraction (437 articles) in the green cluster, in vitro (366 articles) in the red cluster, and optimization (258 articles) in the yellow cluster, which only has two keywords. We excluded HPLC with 539 articles as its size overwhelms the map and is redundant as all articles relate to HPLC. We also excluded antioxidant (380 articles) as it also takes up too much space, ID (174), LC (102), chromatography (58), and performance (58). The smallest circles represent 79 articles (meaning that, of the 8850 articles, 79 included these as keywords) and include adsorption and NMR in the red cluster and serum, pharmaceuticals, and capillary electrophoresis in the green cluster. The software assigns colours to keywords that are related and positions them in close proximity

hoise (actual peak) and the LOQ is the smallest amount quantified with a certain level of confidence. $\frac{[879]}{}$ Prior to 2012 , literature reported that the signal for quantitative analyses be 10 times that of the noise (LOQ), whereas for qualitative work the minimum detectable signal is 2-3 times the noise (LOD). However, Meyer et al demonstrated that repeatability with an error of $\pm 2 \%$ (combination of injection, chromatographic separation, and integration of peaks) is only possible with a $\mathrm{S} / \mathrm{N}$ of at least 50.80

The response factor (RF) is ratio between the signal generated by an analyte and its corresponding quantity. Each molecule exhibits unique linear detector responses for a range of concentrations. The upper limit of linearity varies by compound as it relates to the specific parameter of detection (e.g., molar absorptivity for UV-Vis detectors). A RF slower than the rate of change of solute in the detector flow cell distorts the output chromatogram (broadening, tailing, flattening). For accurate detection and quantification, the concentration of the analyte(s) must be above the LOQ and within the linear range.
If the concentration is below the $\mathrm{LOQ}$, it is not possible to discriminate between signal and noise. In this case, the sample is too diluted and needs to be concentrated (e.g., evaporation). If the concentration of the sample is above the linear range, it needs to be diluted.

\subsection{Calibration}

We calibrate the instrument by repeating analyses of a standard multiple times from the same or different vials. Based on these repeat runs, we calculate the mean and standard deviation. We calibrate the method with multiple standards at a range of concentrations within the linear response range of the detector and generate a calibration curve. ${ }^{[81}$ The method standard is based on the difference between the ensemble of the measured values and the best fit linear regression. The calibration of the method refers to generating a curve that correlates concentration and detector response. ${ }^{[78}$ For example, we measured 
four concentrations of isoproturon (3-(4-isopropylphenyl)-1,1dimethylurea) three times in sequence: $6 \mu \mathrm{g} \mathrm{g}^{-1}, 12.5 \mu \mathrm{g} \mathrm{g}^{-1}$, $25 \mu \mathrm{g} \mathrm{g}^{-1}$, and $50 \mathrm{\mu g} \mathrm{g}^{-1}$ (Figure 6). The sample standard deviation for each of the four concentrations was $s_{1}=0.0006, s_{2}=$ $0.002, s_{3}=0.002$, and $s_{4}=0.3$, respectively. These values represent the instrument standard deviation. To calculate the standard deviation in the calibration, we could either prepare 12 solutions (three solutions at each concentration) and then calculate $s_{i}$ for each, or prepare four solutions and calculate $s$ from the calibration curve. The calibration curve reduces the number of solutions to prepare by a factor of 3 . We first derive the calibration curve based on the average of the three measurements at each concentration. We ensure that the relationship is linear over the entire range for which the response, $y_{i}$, is proportional to the measured concentration, $x_{i}$ plus a residual (or error), $e_{i}{ }^{[7][54]}$ :

$$
y_{i}=\beta_{0}+\beta_{1} x_{i}+e_{i}
$$

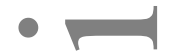

We apply the method of least squares to fit the regression coefficients $\beta_{0}$ (intercept) and $\beta_{1}$ (slope), then equate the sum of the squares of the residuals to the difference between the regressed concentration, $y_{i}$ and the equation (Equation (5):

$$
S S_{e}=\sum_{i=1}^{n} e_{i}^{2}=\sum_{i=1}^{n}\left(y_{i}-\beta_{0}-\beta_{1} x_{i}\right)^{2} .
$$

We then take the partial differential of Equation (6) with respect to $\beta_{0}, \beta_{1}$ and solve to get the regression coefficients:

$$
\begin{aligned}
& \frac{\partial}{\partial \beta_{0}} S S_{e}=-2 \sum_{i=1}^{n}\left(y_{i}-\beta_{0}-\beta_{1} x_{i}\right)=0, \\
& \frac{\partial}{\partial \beta_{1}} S S_{e}=-2 \sum_{i=1}^{n}\left(y_{i}-\beta_{0}-\beta_{1} x_{i}\right)^{2} x_{i}=0 .
\end{aligned}
$$

The difference between the response, $y_{i}$, and the regression equation, $\hat{y}_{i}$, varies from $-0.42-0.27$ (Table 7 ). and the sample deviation of these four values is $s_{\delta_{i}}=0.4$.

TABLE 7 Isoproturon calibration curve

\begin{tabular}{ccccc}
\hline $\begin{array}{c}x_{i} \\
\left(\mu \mathrm{g} \mathrm{g}^{-1}\right)\end{array}$ & $\begin{array}{c}y_{i} \\
\text { Response }\end{array}$ & $s_{i}$ & $\begin{array}{c}\hat{y}_{i} \\
\text { Regression }\end{array}$ & $\begin{array}{c}\delta_{i} \\
y_{i}-\hat{y}_{i}\end{array}$ \\
\hline 6 & 11.12 & 0.0006 & 10.92 & 0.20 \\
12.5 & 22.38 & 0.002 & 22.74 & -0.36 \\
25 & 45.06 & 0.002 & 45.48 & -0.42 \\
50 & 91.24 & 0.3 & 90.97 & 0.27 \\
\hline
\end{tabular}

The variance of the mean of the calibration responses is inversely proportional to the number of points of the calibration line. ${ }^{82}$

The most common method-calibration techniques are external standardization and internal standardization. The external

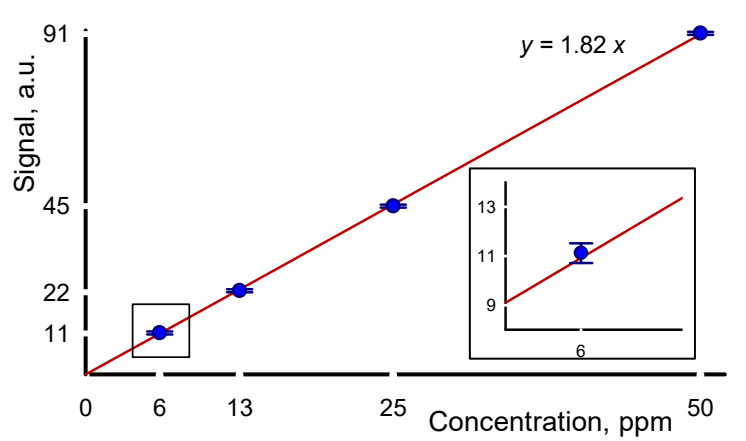

FIGURE 6 External standard calibration with isoproturon (IPU). We prepared samples of IPU at four concentrations then ran the HPLC with an autosampler sequentially. The standard deviation at the lowest concentration was 0.0006 . The standard deviation of the measured values with respect to the fitted calibration curve is $0.4 \%$ of the full scale reading. We assumed that the intercept passed through the origin and so set $\beta_{0}=0$. The insert is an expanded view of the lowest concentration to better illustrate the error bars $(n=4)$

standard (ES) calibration method generates a calibration curve of the absolute analyte response against the concentration of the analyte. This method is reliable when sample preparation and injection volume errors are minimal. ${ }^{[83]}$ When the analyte is soluble and stable in the mobile phase and when the sample work-up is simple, we adopt the ES method. ${ }^{84}$ For optimal results, the concentration of samples should fall in the range of the standard solutions of the calibration curve, preferably in the linear range.

For quantitative chromatography, the internal standard (IS) method improves the precision of the analysis. This method correlates the ratio of the analyte response to the response of the IS with the ratio of the analyte amount to the IS amount. 83, 85

The standard additions method (SA) is recommended when the analyte is in a complex mixture, the matrix contains components that interfere with the analyte signal, and the blank sample is not available (e.g., biological fluids and soil samples). The SA method splits the sample in several even aliquots and adds the analyte to each aliquot minus one (spiking). The variation of the response between the sample and the spiked samples relates only to changes in analyte concentration. [2] The SA method is practical when the blank samples are not available, and the concentration of the analyte is close to the LOQ. Snyder et al. present a detailed chapter on method calibration and validation [2] 


\section{3 | Stationary phase}

The adsorbent material of HPLC columns has intrinsic limitations. Silica supports are efficient and selective but dissolve when the $\mathrm{pH}$ of the mobile phase rises above 8 , especially in the presence of phosphates. Certain silicas are stable up to a $\mathrm{pH}$ of 10 because of their preparation method and the presence of impurities. 86

Polystyrene (PS), methacrylate, and carbohydrate (e.g., agarose) polymeric supports are stable at a $\mathrm{pH}$ of 2-12. However, their drawback is their limited pressure stability. Agarose is hydrophilic but unstable at higher pressure; its porosity depends on the solvent and pressure. In contrast, PS crosslinked with divinylbenzene is hydrophobic, rigid, and resists up to $34.5 \mathrm{MPa}$, but swells in water or alcohol. [50] Methacrylates are a compromise between hydrophobicity/hydrophilicity and pressure resistance.

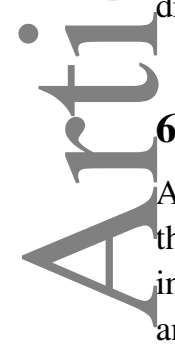

\section{4 | Design of experiments (DOE)}

After selecting columns, mobile phase, detectors, and dilution the final step in creating a method is to set the conditions of the instrument: concentration of the mobile phase, $C$; flow rate, $Q$; and temperature (or define a temperature ramp) (Appendix A) . To optimize these parameters precisely requires a design of experiments (DOE), but in our group, we often rely on experience and a couple of tests to gauge the retention time and peak shape. Other parameters to consider include preparation, concentration, and sample stability. If a test only takes 15 minutes, then running a DOE might not save much time as it can take a day to complete a DOE. However, in the case of lengthier andlyses, the time savings can be substantial; for example, our HPLC operates continuously and one of the programs takes 2 hours. In one year, we analyzed 700 samples, so if we could have cut the run time in half, we would have saved 700 hours (one month). Reducing the run time by a factor of 2 certainly justifies one week's worth of tests to optimize the method.

We chose isoproturon (IPU) as our test compound to complete a DOE, whose purpose was to identify the relationship between three factors (temperature, flowrate, and solvent concentration) and two response variables (peak shape and retention time). To ensure the DOE identified non-linear relationships and was capable of capturing interactions, we completed a full factorial with three levels for each factor. ${ }^{[7]}$ This design requires $3^{3}$ tests $(n=27)$. Response variables that vary linearly with factors require only two levels. In this case, if response variables varied linearly with factors, the design would only require eight experiments $\left(n=2^{3}=8\right)$. We selected $0.2 \mathrm{~mL} \mathrm{~min}^{-1}, 0.5 \mathrm{~mL} \mathrm{~min}^{-1}$, and $0.8 \mathrm{~mL} \mathrm{~min}^{-1}$ for $Q$; $20^{\circ} \mathrm{C}, 30^{\circ} \mathrm{C}$, and $40^{\circ} \mathrm{C}$ for $T$; and $20 \%, 50 \%$, and $80 \%$ for $C_{\mathrm{ACN}}$ (Table 8). We repeated each run to have an idea of reproducibility, so the total DOE consisted of 54 tests and it took

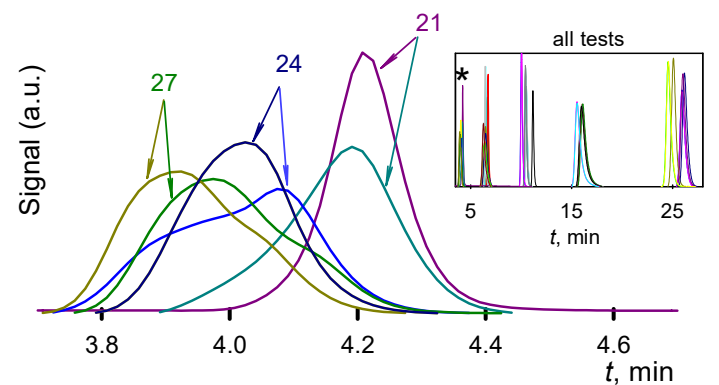

FIGURE 7 Isoproturon (IPU) elution as a function of temperature at the highest flow rate and the highest $C_{\mathrm{ACN}}$. The $t_{\mathrm{R}}$ decreases slightly with increasing temperature, which is desirable, but reproducibility is poor at these conditions and the peaks have extended leading edges and double peaks (shoulders)

\begin{tabular}{cccc} 
Test & $\begin{array}{c}C_{\mathrm{ACN}} \\
(\mathrm{vol} \%)\end{array}$ & $\begin{array}{c}T \\
\left({ }^{\circ} \mathrm{C}\right)\end{array}$ & $\begin{array}{c}Q \\
\left(\mathrm{~mL} \mathrm{~min}^{-1}\right)\end{array}$ \\
\hline 21 & 80 & 20 & 0.8 \\
24 & 80 & 30 & 0.8 \\
27 & 80 & 40 & 0.8
\end{tabular}

well over one week to complete. Experimental designs must target a wide range of conditions in order to ensure that all effects are captured. However, at times, too broad a range compromises the data quality, as it did in this case. The IPU eluted at up to 120 minutes with low concentrations of acetonitrile $(\mathrm{ACN})\left(C_{\mathrm{ACN}}=20 \%\right)$. So, we were forced to remove most of the tests from the design.

Graphing the data is the first step in sorting out important effects and it helps to identify anomalies like peak tailing and shoulders. We have magnified the time scale of Figures 7-11 to better differentiate features of each peak that are masked with an expanded time scale. The insert in the figures show that five clusters of peaks appear symmetrical. However, several peaks in Figure 7 have substantial shoulders as large at the main peak. Most of the peak in Figure 8 are symmetrical but some are sharp with a peak-width at half height of 0.2 minutes, while others extend over 0.5 minutes. Peaks in Figure 9 are reasonably well defined, while in Figure 10, the tail extends over 1 minute. Although we favour short retention times, both symmetry and reproducibility were poorest for tests where $t_{\mathrm{R}}<5 \mathrm{~min}$ (Figure 7 ). These tests operated at the highest flow rate and highest $C_{\mathrm{ACN}}$.

Symmetry was excellent with some tests in which $t_{\mathrm{R}}<7$ minutes; the peaks were broader and shorter with a higher concentration of $C_{\mathrm{ACN}}$ and lower $Q$ (Figure 8 ). 


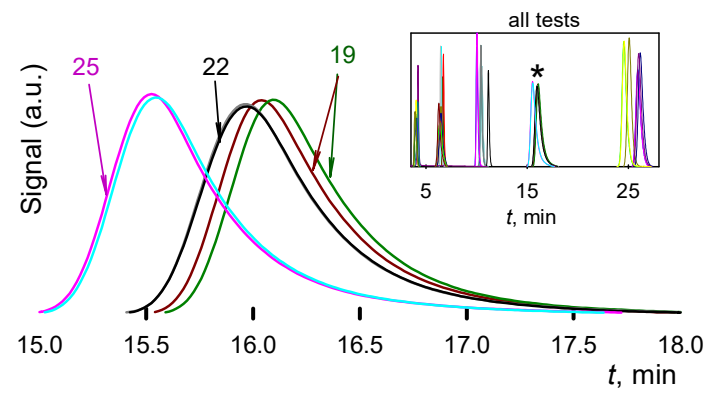

FIGURE 10 Isoproturon (IPU) elution as a function both low flow rate and high $C_{\mathrm{ACN}}$ (tests 19, 22, 25). Increasing temperature moderately reduces elution time by $1 \mathrm{~min}$. The repeat runs of Tests 22 and 25 are virtually identical to the first runs. All peaks have a significant trailing edge

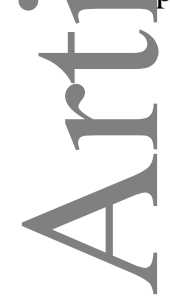

\begin{tabular}{cccc} 
Test & $\begin{array}{c}C_{\mathrm{ACN}} \\
(\mathrm{vol} \%)\end{array}$ & $\begin{array}{c}T \\
\left({ }^{\circ} \mathrm{C}\right)\end{array}$ & $\begin{array}{c}Q \\
\left(\mathrm{~mL} \mathrm{~min}^{-1}\right)\end{array}$ \\
\hline 19 & 80 & 20 & 0.2 \\
22 & 80 & 30 & 0.2 \\
25 & 80 & 40 & 0.2
\end{tabular}

A non-linear statistical model with three factors includes second order terms and has 54 fitted parameters, which is cumbersome to work with. To reduce the number of parameters, we identify factors that have no interactions and then delete these from the model. However, to quickly identify the major contributions to the variance in the data, we apply a non-linear power-law model with four fitted parameters rather than 54 :

$$
t_{\mathrm{R}}=\beta_{0} C_{\mathrm{ACN}}^{\beta_{1}} T^{\beta_{2}} Q^{\beta_{3}}
$$

We first included the full data set to help identify outliers and then confirm which to ignore based on the difference between the predicted and experimental measurements. Typically, the difference in retention times of repeat runs are less than 0.1 minutes. The difference in the $t_{\mathrm{R}}$ between the repeat runs in experiment 21 is 0.8 minutes and it is 4.5 minutes in experiment 15 (Table 8). We rejected these two runs and so our final data set consisted of 35 tests. The best fit values of $\beta_{1}$ and $\beta_{3}$ were -1 . It is intuitive (obvious) that the retention time decreases linearly with increasing liquid velocity. Less intuitive is how $t_{\mathrm{R}}$ varies with $C_{\mathrm{ACN}}$. If we had known that both these factors were linear, the number of experiments would have been $n=2 \times 3 \times 2=12$ rather than $n=3 \times 3 \times 3=27$. The best fit value for temperature was $\beta_{2}=-0.05$. The plots in the figures confirm that temperature only has a marginal effect on $t_{\mathrm{R}}$ compared to $Q$ and $C_{\mathrm{ACN}}$, so we could also ignore this

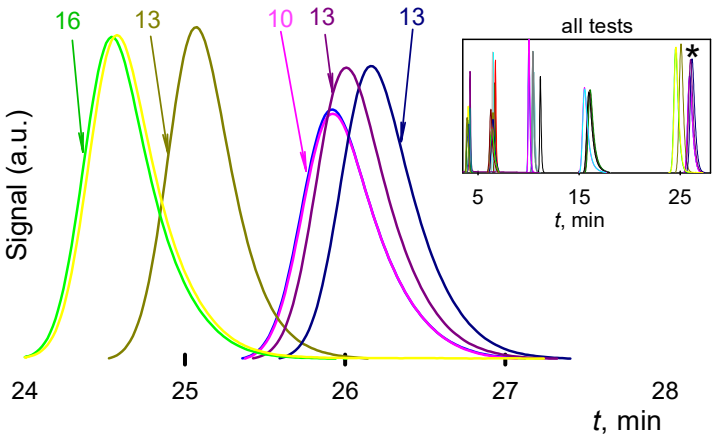

FIGURE 11 Isoproturon (IPU) elution as a function both low flow rate and medium $C_{\mathrm{ACN}}$ (tests 10, 13, 16). Increasing temperature moderately reduces elution time by $2 \mathrm{~min}$. The repeat runs of tests 10 and 16 are virtually identical to the first runs but the repeat runs of test 13 vary by $1 \mathrm{~min}$. The trailing edge of these peaks are less pronounced than in Figure 10, which operated with a higher $C_{\mathrm{ACN}}$

\begin{tabular}{cccc} 
Test & $\begin{array}{c}C_{\mathrm{ACN}} \\
(\mathrm{vol} \%)\end{array}$ & $\begin{array}{c}T \\
\left({ }^{\circ} \mathrm{C}\right)\end{array}$ & $\begin{array}{c}Q \\
\left(\mathrm{~mL} \mathrm{~min}^{-1}\right)\end{array}$ \\
\hline 10 & 50 & 20 & 0.2 \\
13 & 50 & 30 & 0.2 \\
16 & 50 & 40 & 0.2
\end{tabular}

factor and drop the number of experiments in the DOE to four experiments (five including one repeat):

$$
t_{\mathrm{R}}=\frac{3}{C_{\mathrm{ACN}} Q T^{0.05}} \quad R^{2}=0.9995
$$

This power-model advocates increasing flow rate and $C_{\mathrm{ACN}}$ to reduce $t_{\mathrm{R}}$, but the quality and reproducibility of the peaks below 5 minutes is unacceptable (Figure 77). To identify the optimal operating conditions requires us to examine another parameter. For multicomponent systems, the obvious parameter is resolution (peak separation), but here we limited the analysis to a single component. So, as an alternative we considered the ratio of the peak width at half the peak height to the retention time to $\left(W_{1 / 2} / t_{\mathrm{R}}\right)$. The peak widths below $t_{\mathrm{R}}<$ 4 minutes are narrower than at longer times, but this ratio is higher, which is due to the shoulders and the extended leading edge (Figure 7) tests 21, 24, 27). Tests 20, 23, and 26 (Figure 7) have long trailing tails and consequently the ratio is also high. Tests 12,15 , and 18 have approximately the same $t_{\mathrm{R}}$, but their peaks are more symmetrical and as a consequence $W_{1 / 2} / t_{\mathrm{R}}$ is half that of tests 20,23, and 26. Tests 10 and 13 have the lowest ratio but they also have the longest residence time. 
To identify the optimal peak shape, we again applied a power-law model. The best fit exponent on $C_{\mathrm{ACN}}$ was 2 , but it was only 0.3 for $Q$, and negligible for $T$ :

$$
\frac{W_{1 / 2}}{t_{\mathrm{R}}}=C_{\mathrm{ACN}}^{2} Q^{0.3}
$$

Finally, to establish optimal conditions for flow rate, concentration, and temperature, we combine Equations 11 and 12 , differentiate with respect to each factor, and solve the set of equations:

$$
f=\alpha_{1} t_{\mathrm{R}}+\alpha_{2} \frac{W_{1 / 2}}{t_{\mathrm{R}}}=\alpha_{1} \frac{0.26}{C_{\mathrm{ACN}} Q}+0.1 \alpha_{2} C_{\mathrm{ACN}}^{2} Q^{0.3}
$$

where $\alpha_{1}$ and $\alpha_{2}$ are weighting factors that we choose somewhat arbitrarily. A first approximation would be to take the means over the truncated data set: $\alpha_{1}=\bar{t}_{\mathrm{R}}$ and $\alpha_{2}=\bar{W}_{1 / 2} / t_{\mathrm{R}}$. The equations to identify the optimum $C_{\mathrm{ACN}}$ and $Q$ are as

- follows:

$$
\begin{aligned}
\frac{\partial f}{\partial C} & =\frac{0.26}{C_{\mathrm{ACN}}^{2} Q}+0.2 \alpha_{2} C_{\mathrm{ACN}} Q^{0.3}=0 \\
\frac{\partial f}{\partial Q} & =-\alpha_{1} \frac{0.26}{C_{\mathrm{ACN}} Q^{2}}+0.03 \alpha_{2} \frac{C_{\mathrm{ACN}}}{Q^{0.7}}=0
\end{aligned}
$$

Because the exponent of $C_{\mathrm{ACN}}$ for $W_{1 / 2} / t_{\mathrm{R}}$ equals 2 , the DOE requires three levels. Our truncated design eliminated all tests at $C_{\mathrm{ACN}}=20 \%$, which reduces the design to two levels for $C_{\mathrm{ACN}}$, so the model is incapable of establishing the mathematical optimum with this data set. Although Equation 12 has a high $R^{2}$, it applies only to tests at $C_{\mathrm{ACN}}=50 \%$ and $80 \%$ (Figures 9 and 10 ). The equation is inapplicable at $C_{\mathrm{ACN}}=20 \%$ as it predicts that $W_{1 / 2} / t_{\mathrm{R}}$ is $1 / 5 \times$ the experimental value. So, we caution against blindly applying ontimization outside the range of the data.

Rather than an optimization strategy, in practice, we choose operating parameters (factors) that minimize $t_{\mathrm{R}}$ for which the peak shape $\left(W_{1 / 2} / t_{\mathrm{R}}\right)$ looks acceptable (no shoulders or tailing). Tests 12 and 18 come out before 7 minutes and the peaks are symmetrical and narrow $\left(W_{1 / 2} / t_{\mathrm{R}}=0.02\right)$. Since it is easier to work at ambient temperature versus heating the system, we recommend the conditions of test 12 for the method. Ideally, rather than retention time, the primary variable should be resolution. The ideal full factorial design would be three levels for $C_{\mathrm{ACN}}$ and two levels for $T$ and $Q: 3 \times 2 \times 2=12+1$ repeat $=13$ tests. We could reduce the number of tests from 13 to seven with a partial factorial design with a generating function, which is the product of the levels of two factors that we apply to the third factor $\left(C_{\mathrm{ACN}} \times T\right.$ for the conditions of $Q-$ Table 9 ).

Because of the uncharacteristically long retention times at $C_{\mathrm{ACN}}=20 \%$, we increased its concentration in the final design.

As a final confirmation exercise, we selected the maximum and minimum conditions for $C_{\mathrm{ACN}}$ and $Q$ in a $2 \times 2$ factorial design (50\% and $80 \%$ for $C_{\mathrm{ACN}}$ and $0.2 \mathrm{~mL} \mathrm{~min}^{-1}$ and
TABLE 9 Partial factorial design with a generating function of $C_{\mathrm{ACN}} \times T$ for the conditions of $Q$, where + and - are the maximum and minimum conditions for each factor and 0 is the mid-point for $C_{\mathrm{ACN}}$

\begin{tabular}{ccc|ccc}
\hline$C_{\mathrm{ACN}}$ & $T$ & $Q$ & $\begin{array}{c}C_{\mathrm{ACN}} \\
(\%)\end{array}$ & $\begin{array}{c}T \\
\left({ }^{\circ} \mathrm{C}\right)\end{array}$ & $\begin{array}{c}Q \\
\left(\mathrm{~mL} \mathrm{~min}^{-1}\right)\end{array}$ \\
\hline+ & + & + & 80 & 40 & 0.8 \\
0 & + & + & 55 & 40 & 0.8 \\
- & + & - & 30 & 40 & 0.2 \\
+ & - & - & 80 & 20 & 0.2 \\
0 & - & - & 55 & 20 & 0.2 \\
- & - & + & 30 & 20 & 0.8 \\
\hline
\end{tabular}

$0.8 \mathrm{~mL} \mathrm{~min}^{-1}$ for $Q$, respectively). The fitted parameters to the power law model with this design were 2.6 and -1 for each of the exponents on $C_{\mathrm{ACN}}$ and $Q$, which is identical to those we derived with the truncated data design with 35 tests. Moreover, we calculated the standard deviation between predicted and experimental data for both designs and they were the same at 0.1 minute. So, ignoring experimental blunders, the repeatability of the retention time of IPU according to this method is excellent and any deviation of a repeat run greater than 0.1 minute is suspect.

\section{7 | CONCLUSIONS}

HPLC is a flexible analytical tool applied in chemistry, biology, medicine, materials, and chemical engineering. It is constantly evolving to meet ever more demanding specifications (drug testing for Olympic athletes, for example), from highthroughput and high-resolution to flexibility and mechanical robustness. These advances concern the development of innovative stationary phases, such as core-shell or fused-core packings, or pellicular beads, that decouple the retentive distances in the particle from the hydraulic distances between particles for increased efficiency and permeability. ${ }^{[87]}$ HPLC is versatile and is often combined with other techniques. Recently, uncommon hyphenated techniques such as LC-FTIR, LC-AAS, and LC-NMR have emerged. HPLC's adaptability has also promoted the design of innovative analytical approaches. For instance, Campisi et al and Ferri et al set up a LC technique to determine the surface acidity/basicity of solid materials in liquids. 88,90

HPLC is a robust technique whose accuracy and repeatability continue to improve. Operator oversight, such as applying solvents incompatible with the mobile phase/stationary 
phases, ineffective filtering (that introduces impurities), insufficient sonication, unstable samples, and inappropriate chromatographic detection modes and columns are among the most common sources of error. These errors include baseline drift, tailing, peak broadening, and retention time shift. Refractive index detectors are more sensitive to temperature and pressure variation than UV-Vis or radioactivity detectors. We anticipate that reproducibility of the retention time is better than $\pm 1 \%$. Calibration curve reproducibility is on the order of $\pm 0.5 \%$. When repeat traces deviate by more than a couple percent, standard practice is to run a third trace and average the two that are closest. Other strategies to reduce errors include weekly calibration with a standard solution (to identify column bleeding, or other physical damage to the column or the detector); C washing the column, injection syringe, and injection loop with every new system; and using new vials and syringe filters.

A literature review is the first step to develop a robust Jmethod. Preliminary chromatograms assess which parameters need optimization to improve resolution and minimize run time. Here we applied a full factorial DOE to identify the optimal flow rate, temperature, and mobile phase concentration. We showed that retention time is inversely proportional to flow rate and $C_{\mathrm{ACN}}$ concentration while the peak shape $\left(t_{\mathrm{R}} / W_{1 / 2}\right)$ varies with $C_{\mathrm{ACN}}$ to the power of 2. Consequently, the DOE requires at minimum seven experiments, or 13 experiments if we account for temperature (which has only a minor contribution to the peak shape and retention time). The standard deviation of the retention time for the complete set of experiments was only 0.1 minute.

\section{NOMENCLATURE}

AAS atomic absorption spectroscopy

$\mathrm{ACN}$ acetonitrile

C

$d_{\mathrm{c}}$

$d_{\mathrm{p}}$

DAD

DMSO

concentration (vol\% in $\mathrm{H}_{2} \mathrm{O}$ )

column diameter $(\mathrm{mm})$

particle diameter $(\mu \mathrm{m})$

diode array detector

dimethyl sulfoxide

ELSD evaporative light scattering detector

ES external standard

$F \quad$ flow rate $\left(\mathrm{mL} \mathrm{min}^{-1}\right)$

FTIR Fourier-transform infrared spectroscopy

HC hydrocarbon

HPLC high performance liquid chromatography

IS internal standard

$k \quad$ retention factor

$L \quad$ length of the column (mm)

\begin{tabular}{|c|c|}
\hline LOD & limit of detection \\
\hline MW & molecular weight $\left(\mathrm{g} \mathrm{mol}^{-1}\right)$ \\
\hline MALLS & multi-angle laser scattering detector \\
\hline$n$ & number of experiments \\
\hline$n_{\mathrm{i}}$ & refractive index, dimensionless \\
\hline$Q$ & volumetric flow rate $\left(\mathrm{mL} \min ^{-1}\right)$ \\
\hline $\mathrm{N}$ & number of points \\
\hline NMR & nuclear magnetic resonance \\
\hline PP & polypropylene \\
\hline PTFE & polytetrafluoroethylene \\
\hline PVDF & polyvinylidene fluoride \\
\hline $\mathrm{r}$ & residual \\
\hline $\mathrm{R}$ & resolution \\
\hline $\mathrm{RC}$ & regenerated cellulose \\
\hline RI & refractive index detector \\
\hline $\mathrm{RP}$ & reverse phase \\
\hline$R_{\theta}$ & Rayleigh factor \\
\hline s & residual standard deviation \\
\hline SEC & size exclusion chromatography \\
\hline $\mathrm{S} / \mathrm{N}$ & signal to noise ratio \\
\hline$t_{\mathrm{R}}$ & retention time (min) \\
\hline TFA & trifluoroacetic acid \\
\hline THF & tetrahydrofuran \\
\hline $\bar{u}_{\mathrm{i}}$ & analyte flow rate $\left(\mathrm{mL} \mathrm{min}{ }^{-1}\right)$ \\
\hline $\bar{u}_{\mathrm{M}}$ & mobile phase flow rate $\left(\mathrm{mL} \mathrm{min}^{-1}\right)$ \\
\hline $\mathrm{UV}-\mathrm{Vis}$ & ultraviolet-visible detector \\
\hline$W_{1 / 2}$ & peak width at half the peak height (min) \\
\hline $\begin{array}{l}\text { Greek Lett } \\
\alpha \text { we }\end{array}$ & ighting factor (Equations $(11$ and 12$)$ \\
\hline$\Delta P$ & ssure drop $(\mathrm{Pa})$ \\
\hline vis & $\operatorname{cosity}\left(\mathrm{Pa} \mathrm{s}^{-1}\right)$ \\
\hline mo & ar extinction coefficient $\left(\mathrm{m}^{2} \mathrm{~mol}^{-1}\right)$ \\
\hline$\lambda_{\text {co }}$ & -off wavelength (nm) \\
\hline$\lambda_{\mathrm{ex}}$ & itation wavelength (nm) \\
\hline$\lambda_{\mathrm{em}}$ & ission wavelength (nm) \\
\hline
\end{tabular}

\section{References}

[1] M. S. Tswett, Berichte der Deutschen botanischen Gesellschaft 1906, 24, 316.

[2] L. R. Snyder, J. J. Kirkland, J. W. Dolan, Introduction to Modern Liquid Chromatography, 3rd edition, Wiley, Hoboken, New Jersey 2009.

[3] E. Heftmann, Chromatography fundamentals and applications of chromatographic and electrophoretic methods, volume 22 of Journal of Chromatography Library, Elsevier 1983, pp. A19-A26.

[4] C. H. Arnaud, C\&EN Glob. Enterp. 2016, 94, 28.

[5] G. S. Patience, Can. J. Chem. Eng. 2018, 96, 2312. 
[6] D. Belan, S. Lucini, C. Neagoe, P. Perreault, F. Galli, G. S. Patience, Experimental Methods and Instrumentation for Chemical Engineers, 2nd edition, Elsevier B.V., Amsterdam, Netherlands 2018, pp. 263-292.

[7] G. S. Patience, Experimental Methods and Instrumentation for Chemical Engineers, 2nd edition, Elsevier B.V., Amsterdam, Netherlands 2017.

[8] L. R. Snyder, J. J. Kirkland, J. L. Glajch, Practical HPLC Method Development, 2nd edition, John Wiley \& Sons, Hoboken, New Jersey 2012.

[9] Y. Okamoto, T. Ikai, Chem. Soc. Rev. 2008, 37, 2593.

[10] D. Corradini, E. Eksteen, R. Ekstee, P. Schoenmakers, N. Miller, Handbook of HPLC, CRC Press, New York 2011.

11] D. Carnevali, M. G. Rigamonti, T. Tabanelli, G. S. Patience, F. Cavani, Appl. Catal. A: Gen. 2018, 563, 98.

12] S. Mori, H. G. Barth, Size Exclusion Chromatography, Springer Science, Berlin 2013.

13] A. Hauser, M. Penkert, C. P. R. Hackenberger, Accounts Chem. Res. 2017, 50, 1883.

14] M. Haberger, M. Leiss, A.-K. Heidenreich, O. Pester, G. Hafenmair, M. Hook, L. Bonnington, H. Wegele, M. Haindl, D. Reusch, P. Bulau, $m A b s$ 2016, 8, 331.

15] M. Verzele, J. V. Dijck, P. Mussche, C. Dewaele, J. Liq. Chromatogr. 1982, 5, 1431.

M. Verzele, C. Dewaele, J. High Resolut. Chromatogr. 1982, 5,245 .

[17] M. R. Schure, R. S. Maier, J. Chromatogr. A 2006, 1126, 58.

18] S. Fanali, P. R. Haddad, C. Poole, M.-L. Riekkola, Liquid Chromatography, Elsevier, Oxford 2017.

[19] R. Bennett, S. V. Olesik, J. Chromatogr. A 2017, 1523, 257.

[20] M. R. Euerby, P. Petersson, W. Campbell, W. Roe, J. Chromatogr. A 2007, 1154, 138 .

[21] V. González-Ruiz, A. I. Olives, M. A. Martín, Trends Anal. Chem. 2015, 64, 17.

[22] B. M. Wagner, S. A. Schuster, B. E. Boyes, T. J. Shields, W. L. Miles, M. J. Haynes, R. E. Moran, J. J. Kirkland, M. R. Schure, J. Chromatogr. A 2017, 1489, 75.

[23] J. J. Lander, W. J. Svirbely, J. Am. Chem. Soc. 1945, 67, 322.
[24] V. Balachandran, K. Parimala, Spectrochimica Acta Part A: Mol. Biomol. Spectrosc. 2012, 95, 354.

[25] C. Seaver, P. Sadek, LC GC Mag. 1994, 12, 742.

[26] F. S.Rocha, A. J. Gomes, C. N. Lunardi, S. Kaliaguine, G. S. Patience, The Can. J. Chem. Eng. 2018, 96, 2512.

[27] S. Lupo, T. Kahler, LC GC North Am. 2017, 35, 5424.

[28] S. Ahuja, H. Rasmussen, HPLC Method Development for Pharmaceuticals, Academic Press, London 2008.

[29] J. van Deemter, F. Zuiderweg, A. Klinkenberg, Chem. Eng. Sci. 1956, 5, 271.

[30] M. H. Chen, C. Horváth, J. Chromatogr. A 1997, 788, 51

[31] J. Khonmee, J. L. Brown, M.-Y. Li, C. Somgird, K. Boonprasert, T. Norkaew, V. Punyapornwithaya, W.-M. Lee, C. Thitaram, Conserv. physiology 2019, 7, coz031.

[32] M. Heidorn, Thermo Fish. Sci. 2015, White Paper. URL http://tools.thermofisher. com/content/sfs/brochures/ WP-71499-LC-Temperature-Column-Thermostatting-W/P71499-E pdf

[33] T. Macko, H. Pasch, Macromol. 2009, 42, 6063.

[34] B. J. Marquis, H. P. Louks, C. Bose, R. R. Wolfe, S. P. Singh, Chromatogr. 2017, 80, 1723.

[35] Q. Liu, Q. Chi, R.-T. Fan, H.-D. Tian, X. Wang, Nat. products bioprospecting 2019, 9, 201.

[36] W.-L. Fang, L.-J. Xia, X. Huang, X.-F. Guo, J. Ding, H. Wang, Y.-Q. Feng, Chromatogr. 2018, 81, 1381.

[37] L. F. de Lima, P. F. Brandão, T. A. Donegatti, R. M. Ramos, L. M. Gonçalves, A. A. Cardoso, E. A. Pereira, J. A. Rodrigues, Talanta 2018, 187, 113.

[38] Z. Es'haghi, Photodiodes-Communications, BioSensings, Measurements and High-Energy Physics, inTech, New York 2011.

[39] L. G. de Araujo, F. da Silva Santos, A. C. S. C. Teixeira, The Can. J. Chem. Eng. 2017, 95, 2278.

[40] Z. Khani, D. Schieppati, C. Bianchi, D. Boffito, Catal. 2019, 9, 949.

[41] P. Bansal, A. Verma, K. A. , A. Singh, S. Gupta, The Can. J. Chem. Eng. 2016, 94, 1269.

[42] M. M. M. Bindes, V. L. Cardoso, M. H. M. Reis, D. C. Boffito, J. Food Eng. 2019, 241, 97. 
[43] P. Perreault, E. Robert, G. S. Patience, The Can. J. Chem. Eng. 2019, 97, 1036.

[44] N. Gray, K. Adesina-Georgiadis, E. Chekmeneva, R. S. Plumb, I. D. Wilson, J. K. Nicholson, Anal. Chem. 2016, 88,5742 .

[45] H.-Y. Liu, S.-L. Lin, M.-R. Fuh, Talanta 2016, 150, 233.

[46] D. Schieppati, F. Galli, M.-L. Peyot, V. Yargeau, C. L. Bianchi, D. C. Boffito, Ultrason. Sonochemistry 2019, 54,302 .

[47] V. Yargeau, F. Danylo, Water science technology: a journal Int. Assoc. on Water Pollut. Res. 2015, 72, 491.

48] A. Rodaya, S. Afana, P. A. Segura, T. Sultana, C. D. Metcalfe, V. Yargeau, Environ. Toxicol. Chem. 2016, 35, 843.

[49] B. Hoffmann, S. Münch, F. Schwägele, C. Neusüß, W. Jira, Food Control. 2017, 71, 200.

50] R. L. Cunico, K. M. Gooding, T. Wehr, Basic HPLC and $\mathrm{CE}$ of biomolecules, 3rd edition, Bay Analytical Laboratory, Richmond, CA 1998.

[51] M. O. Guérrero-Pérez, G. S. Patience, M. A. Bañares, The Can. J. Chem. Eng. 2020, 98, 2168.

[52] A. Williams, E. K. Read, C. D. Agarabi, S. Lute, K. A. Brorson, J. Chromatogr. B 2017, 1046, 122.

[53] A. Kokhanovsky, Light Scattering Reviews, Volume 11Light Scattering and Radiative Transfer, 1st edition, Springer, Berlin 2016.

54] A. J. Gomes, C. N. Lunardi, F. S. Rocha, G. S. Patience, The Can. J. Chem. Eng. 2019, 97, 2168.

[55] X. Hu, Y. Liu, R. Yang, Y. aJiang, M. Meng, Z. Liu, L. Ni, W. Wu, H. Liu, The Can. J. Chem. Eng. 2020, 98, 394.

56] L. Chen, F. Wen, M. Li, X. Guo, S. Li, N. Zheng, J. Wang, Food Chem. 2017, 215, 377.

[57] G. Li, S. Liu, Z. Sun, L. Xia, G. Chen, J. You, Food Chem. 2015, 170, 123.

[58] S. A. Çevikkalp, G. B. Löker, M. Yaman, B. Amoutzopoulos, Food Chem. 2016, 193, 26.

[59] M. Kiffe, D. G. Schmid, G. J. M. Bruin, J. Liq. Chromatogr. \& Relat. Technol. 2008, 31, 1593.

[60] T. C.Pinkerton, T. D. Miller, L. J. Janis, Anal. Chem. 1989, 61,1171 .

[61] C. Bordier, The J. Biolgical Chem. 1981, 256, 1604.
[62] B. G. Kitchener, J. Wainwright, A. J. Parsons, Prog. Phys. Geogr. Earth Environ. 2017, 41, 620.

[63] S. R. Bakalyar, C. Phipps, B. Spruce, K. Olsen, J. Chromatogr. A 1997, 762, 167.

[64] Restek, Syringe filters compatibility chart, accessed on 5 March 2020, https://www.restek.com/pdfs/GNTS2122UNV.pdf 2020.

[65] ScientificFilters, Syringe filters compatibility chart, accessed on 5 march 2020, https://scientificfilters.com/wpcontent/uploads/2016/03/Syringe FilterChemicalCompatibility.pdf $\mathbf{2 0 2 0}$.

[66] MilliporeSigma Syringe filters, https://www. sigmaaldrich.com/canada-english.html 2020.

[67] Clarivate Analytics, Web of Science Core Collection, accessed on 05 May 2020, http://apps.webofknowledge.com 2020.

[68] S. Alizadeh, N. Fallah, M. Nikazar, The Can. J. Chem. Eng. 2019, 97, 491.

[69] N. J. van Eck, L. Waltman, Sci. 2010, 84, 523.

[70] A. R. Bagheri, M. Arabi, M. Ghaedi, A. Ostovan, X. Wang, J. Li, L. Chen, Talanta 2019, 195, 390.

[71] F. Tahernejad-Javazmi, M. Shabani-Nooshabadi, H. Karimi-Maleh, Compos. Part B-Engineering 2019, $172,666$.

[72] J. Chen, X. Xio, Y. Wang, Z. Ye, Appl. Surf. Sci. 2019, 467, 1000.

[73] R. Li, M. Cai, Z. Xie, Q. Zhang, Y. Zeng, H. Liujin, G. Liu, W. Lv, Appl. Catal. B-Environmental 2019, 244, 974.

[74] R. Pankaj, A. Sudhaik, P. Singh, P. Shandilya, A. K. Saini, V. K. Gupta, J.-H. Lim, H. Jung, A. HosseiniBandegharaei, Sep. Purif. Technol. 2019, 212, 887.

[75] L. Chen, , X. Zuo, S. Yang, T. Cai, D. Ding, Chem. Eng. J. 2019, 359, 373.

[76] G. S. Patience, C. A. Patience, F. Bertrand, Can. J. Chem. Eng. 2018, 96, 811.

[77] A. D. McNaught, A. Wilkinson, IUPAC. Compendium of Chemical Terminology, online version edition, Blackwell Scientific Publications, Oxford 1997.

[78] M. Kimura, D. B. Rodriguez-Amaya, Arch. latinoamericanos de nutricion 1999, 49, 58S. 
[79] D. A. Armbruster, T. Pry, The Clin. Biochem. Rev. 2008, 29, S49.

[80] C. Meyer, P. Seiler, C. Bies, C. Cianciulli, H. Wätzig, V. R. Meyer, Electrophor. 2012, 33, 1509.

[81] I. O. for Standardization, Int. Lab. Accreditation Coop. 2017, Testing and Calibration Laboratories, 8.

[82] D. B. Hibbert, Analyst 2006, 131, 1273.

[83] K. Usher, S. Hansen, J. Amoo, A. Bernstein, M. McNally, LCGC 2015, 33, 40.

[84] Z.-h. Wang, H.-j. Liu, Z.-w. Fang, X.-z. Zhou, X.-l. Long, The Can. J. Chem. Eng. 2019, 97, 2086.

85] S. Imre, A. Tero-Vescan, M. Dogaru, L. Kelemen, D. Muntean, A. Curticapean, N. Szegedi, C.-E. Vari, J. chromatographic science 2019, 57, 243.

[86] J. Kirkland, M. van Straten, H. Claessens, J. Chromatogr. A 1995, 691, 3 .

[87] G. Rozing, LC GC Eur. 2003, 16A, 14.

88] S. Campisi, S. Bennici, A. Auroux, P. Carniti, A. Gervasini, Top. Catal. 2018, 61, 1939.

89] S. Campisi, M. Ferri, C. Chan-Thaw, F. Sanchez, D. Motta, T. Tabanelli, N. Dimitratos, A. Villa, Nanomater. 2019, 9, 299.

[90] M. Ferri, S. Campisi, M. Scavini, C. Evangelisti, P. Carniti, A. Gervasini, Appl. Surf. Sci. 2019, 475, 397.

[91] C. MacBean, Br. Crop. Prot. Counc. 2008, 59.

[92] M. J. O’Neil, Royal Soc. Chem. 2013, 967.

\section{.

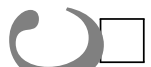 \\ APPENDIX}

\section{A METHOD DEVELOPMENT}

First thing to do: Check the literature! When the literature methods are incomplete or absent, here is a list of items that we address to develop it:

1. Identify sample and stationary phase properties

(a) Sample classification

i. Solid/liquid

ii. Physico-chemical properties (e.g., solubility) iii. Stability (with respect to method and species interactions)

(b) Stationary phase selection

i. Adsorbent material

ii. Particle size

iii. Pore size

2. Mobile phase components
(a) Solvent
(b) Composition
(c) $\mathrm{pH}$ and buffer
(d) Isocratic or gradient elution

3. Column conditions (resolution versus run time)

(a) Temperature

(b) Column length or multiple columns

4. Detector
(a) UV-vis
(b) RI
(c) Fluorescence
(d) MS
(e) Light scattering
(f) Radioactive
(g) Electrochemical

5. Injection

(a) Sample volume

(b) Dilution

(c) Filtration method

6. Verify the reproducibility of the method $(n \geq 3)$

7. Calibration (number of samples, repeats, concentration)

A literature review identifies prior studies and accelerates the method development.

\section{B ISOPROTURON CASE STUDY: HPLC-UV}

The following example demonstrate a structured chromatographic method to quantify the concentration of isoproturon (IPU), a phenyl urea pesticide, during sonophotocatalytic treatment of synthetic wastewater $\left(20 \mathrm{mg} \mathrm{L}^{-1}\right)$. ${ }^{46}$ An HPLC-UV monitored the concentration of IPU over time.

1. Identify the starting conditions 


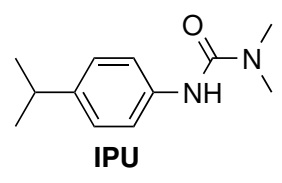

FIGURE B1 Chemical structure of isoproturon (IPU)

(a) Sample classification: Isoproturon (IPU) or 3-(4isopropylphenyl)-1,1-dimethylurea.

i. Solid: White powder/colourless crystals. 91

ii. Physico-chemical properties: Soluble in water; maximum solubility at $20^{\circ} \mathrm{C}$ is $70 \mathrm{mg} \mathrm{L}^{-1}$. 92]

(b) Stationary phase selection: IPU is a polar aromatic urea with $12 \mathrm{C}$ atoms. The best columns are those with a stationary phase similar to IPU (i.e., with high carbon content). C8, C18, or phenyl columns are ideal. We happened to have a Microsorb MV 100-5 C18 column in the lab and it worked. As a general rule, verify if there are any available columns in the lab before before purchasing a new one.

i. Adsorbent material: Octadecyl-silica.

ii. Particle size: $5 \mu \mathrm{m}$.

iii. Pore size: $10 \mathrm{~nm}$.

2. Mobile phase components

(a) Solvent: Literature claimed that water and methanol $(\mathrm{MeOH})$ were appropriate solvents. However, we had a flat line with mixtures of a mass fraction of 20\%-60\% MeOH. Acetonitrile $(\mathrm{ACN})$ is an excellent solvent as it has a lower cut off wavelength and a higher dipole moment $(190 \mathrm{~nm}, 0.60 \mathrm{D})$ than $\mathrm{MeOH}(205 \mathrm{~nm}, 0.28 \mathrm{D})$, and it is predominantly acidic (hydrogen bond donor) contrary to $\mathrm{MeOH}$ which is predominantly basic (hydrogen bond acceptor). ACN was our functional alternative.

(b) Mobile phase composition: $50 \%$ in $\mathrm{H}_{2} \mathrm{O}$.

(c) $\mathrm{pH}$ : Samples denaturate, ionize, and decompose. Often, we adjust the $\mathrm{pH}$ of the mobile phase to maximize stability and enhance resolution. Acidifying the mobile phase with Si based columns, for example, promotes hydrophobic interactions. For our tests, we decided not to acidify the mobilephase as its $\mathrm{pH}$ was already a mildly acidic 5 . Excessive acidification (e.g., pH 2) broadened the peaks of IPU and its byproducts, causing some to elute simultaneously. The neutral form of a

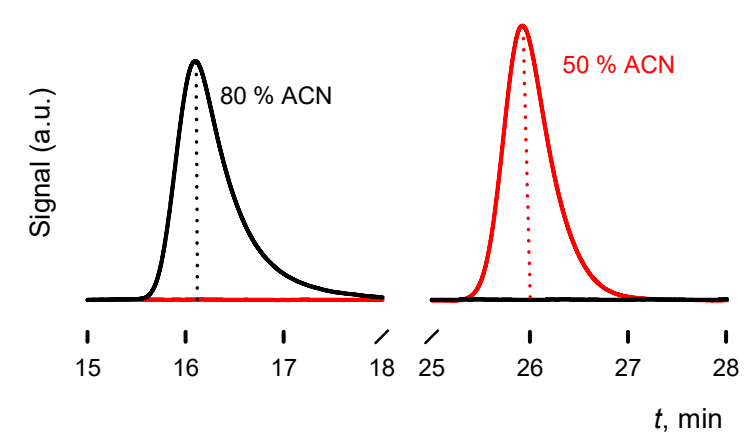

FIGURE B2 High performance liquid chromatographyultraviolet (HPLC-UV) analyses of isoproturon (IPU) at $0.2 \mathrm{~mL} \mathrm{~min}^{-1}$ and $20^{\circ} \mathrm{C}$. Elution by $80 \%$ acetonitrile (ACN) in water and $50 \% \mathrm{ACN}$ in water

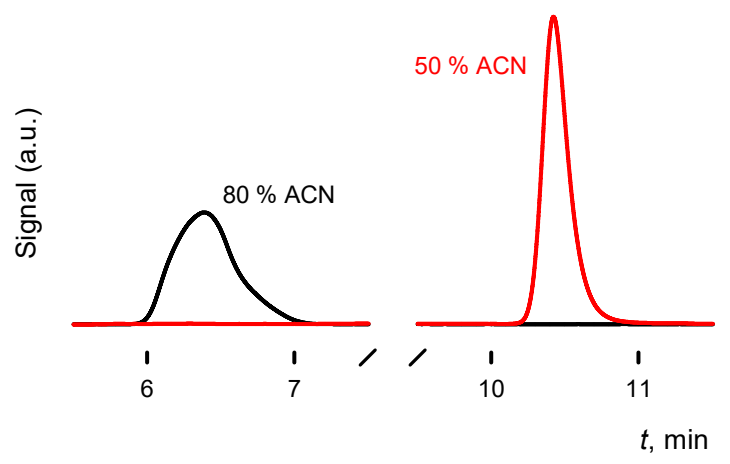

FIGURE B3 High performance liquid chromatographyultraviolet (HPLC-UV) analyses of isoproturon (IPU) at $0.5 \mathrm{~mL} \mathrm{~min}^{-1}$ and $30^{\circ} \mathrm{C}$. Elution by $50 \%$ acetonitrile (ACN) in water or $80 \% \mathrm{ACN}$ in water

molecule usually retains more than its ionic form in RP columns.

i. Buffer: Over time, the $\mathrm{pH}$ of the mobile phase remained stable. We concluded that buffering was unnecessary.

(d) Polarity:

i. Isocratic vs. gradient elution: Older HPLCs operate exclusively with isocratic elution (constant mobile phase composition); we operated at a constant flowrate of $0.5 \mathrm{~mL} \mathrm{~min}^{-1}$ in isocratic mode. Peak broadening is higher at lower flowrates and as 
a result the resolution is poorer. Gradient elution (varying composition of the mobile phase) modifies the polarity throughout the analysis and improves the separation, resulting in better resolution between IPU and the byproducts.

3. Column conditions (length of analysis vs. resolution)

(a) Temperature: Peaks were asymmetrical at $20^{\circ} \mathrm{C}$. Increasing the temperature to $30^{\circ} \mathrm{C}$ and $40^{\circ} \mathrm{C}$ increased the resolution, making it sharp and well defined (Figure B4). Resolution improves with higher temperatures at the expense of stability (degradation rates increase with temperature). Our optimal temperature was $30^{\circ} \mathrm{C}$.

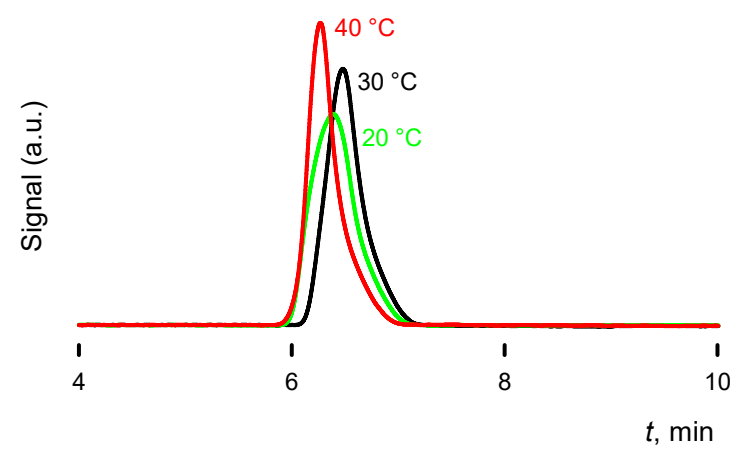

FIGURE B4 High performance liquid chromatographyultraviolet (HPLC-UV) analyses of isoproturon (IPU) at $0.5 \mathrm{~mL} \mathrm{~min}^{-1}$ and $20^{\circ} \mathrm{C}, 30^{\circ} \mathrm{C}$, and $40^{\circ} \mathrm{C}$. Elution by $50 \%$ acetonitrile $(\mathrm{ACN})$ in water

(b) Column length: Columns come in standard lengths ( $250 \mathrm{~mm}$ and $150 \mathrm{~mm}$, for example). Resolution is better with longer columns but analysis time increases. We selected a $250 \mathrm{~mm}$ by $4.6 \mathrm{~mm}$ column.

4. Detector

(a) Our HPLC system is equipped with UV-Vis and RI detectors. Our test compound contains an aromatic ring, which absorbs UV light. Therefore, we selected the DAD detector and set the detection wavelength at the maximum absorption wavelength of IPU $(240 \mathrm{~nm}$, determined separately with a spectrophotometer).
5. Injection

(a) Sample volume: $20 \mu \mathrm{L}$.

(b) Dilution: The maximum concentration before reaction was $20 \mathrm{mg} \mathrm{L}^{-1}$. The external calibration indicated that our samples did not need dilution.

(c) Filtration method: $0.45 \mu \mathrm{m}$ polypropylene filters, appropriate for aqueous samples containing $\mathrm{Cl}$ free organics. The membrane diameter was $10 \mathrm{~mm}$ as we filtered $2 \mathrm{~mL}$ of sample.

6. Verify the reproducibility of the method

(a) Reproducibility: Reproducible.

7. Calibration (Figure 6)

(a) Type of calibration: External.

(b) Number of samples: 4 .

(c) Repeats: 3 .

(d) Concentration: $50 \mathrm{mg} \mathrm{L}^{-1}$ down to $6 \mathrm{mg} \mathrm{L}^{-1}$; dilution 1 to 2 . 